\title{
Determination of Flavonoids Compounds of Three Species and Different Harvesting Periods in Crataegi folium Based on LC-MS/MS
}

\author{
Ya-Ping Guo ${ }^{1} \mathbb{D}$, Hong Yang ${ }^{1}$, Ya-Li Wang ${ }^{2}$, Xiao-Xiang Chen ${ }^{2}$, Ke Zhang ${ }^{2}$, Yan-Li Wang ${ }^{1}$, Yi-Fan Sun ${ }^{1,3}$, \\ Jian Huang ${ }^{1,3, *}$, Lu Yang ${ }^{4, *}$ and Jin-Hui Wang ${ }^{1,2,3}$
}

1 School of Pharmacy, Harbin Medical University, Harbin 150000, China; guoyaping_0816@163.com (Y.-P.G.); yanghonghyd2016@163.com (H.Y.); wangyanli@hrbmu.edu.cn (Y.-L.W.); 17644049614@163.com (Y.-F.S.); wangjinhui@hrbmu.edu.cn (J.-H.W.)

2 Key Laboratory of Xinjiang Phytomedicine Resource and Utilization, Ministry of Education, College of Pharmacy, Shihezi University, Shihezi 832002, China; wyl182em@163.com (Y.-L.W.); chen852110@163.com (X.-X.C.); tcm_zk@163.com (K.Z.)

3 Shenzhen Honghui BioPharmaceutical Co. Ltd., Shenzhen 518118, China

4 Key Laboratory of Forest Resources and Utilization in Xinjiang of National Forestry and Grassland Administration, Xinjiang Academy of Forestry, Key Laboratory of Fruit Tree Species Breeding and Cultivation in Xinjiang, Urumqi 830052, China

* Correspondence: huangjian@hrbmu.edu.cn (J.H.); yanglukitty127@163.com (L.Y.); Tel.: +86-0451-866810032 (J.H.); +86-0991-3733294 (L.Y.)

check for updates

Citation: Guo, Y.-P.; Yang, H.; Wang, Y.-L.; Chen, X.-X.; Zhang, K.; Wang, Y.-L.; Sun, Y.-F.; Huang, J.; Yang, L.; Wang, J.-H. Determination of Flavonoids Compounds of Three Species and Different Harvesting Periods in Crataegi folium Based on LC-MS/MS. Molecules 2021, 26, 1602. https://doi.org/10.3390/

molecules26061602

Academic Editor: Daniela Rigano

Received: 15 February 2021

Accepted: 11 March 2021

Published: 13 March 2021

Publisher's Note: MDPI stays neutral with regard to jurisdictional claims in published maps and institutional affiliations.

Copyright: (c) 2021 by the authors. Licensee MDPI, Basel, Switzerland. This article is an open access article distributed under the terms and conditions of the Creative Commons Attribution (CC BY) license (https:/ / creativecommons.org/licenses/by/ $4.0 /)$.

\begin{abstract}
Crataegi folium have been used as medicinal and food materials worldwide due to its pharmacological activities. Although the leaves of Crataegus songorica (CS), Crataegus altaica (CA) and Crataegus kansuensis (CK) have rich resources in Xinjiang, China, they can not provide insights into edible and medicinal aspects. Few reports are available on the qualitative and quantitative analysis of flavonoids compounds of their leaves. Therefore, it is necessary to develop efficient methods to determine qualitative and quantitative flavonoids compounds in leaves of CS, CA and CK. In the study, 28 unique compounds were identified in CS versus CK by qualitative analysis. The validated quantitative method was employed to determine the content of eight flavonoids of the leaves of CS, CA and CK within $6 \mathrm{~min}$. The total content of eight flavonoids was $7.8-15.1 \mathrm{mg} / \mathrm{g}, 0.1-9.1 \mathrm{mg} / \mathrm{g}$ and $4.8-10.7 \mathrm{mg} / \mathrm{g}$ in the leaves of CS, CA and CK respectively. Besides, the best harvesting periods of the three species were from 17th to 26th September for CS, from 30th September to 15th October for CA and CK. The validated and time-saving method was successfully implemented for the analysis of the content of eight flavonoids compounds in CS, CA and CK for the first time.
\end{abstract}

Keywords: Crataegus songorica; Crataegus altaica; Crataegus kansuensis; LC-MS/MS; flavonoids

\section{Introduction}

Hawthorn is a deciduous tree of Crataegus in family Rosaceae. Seventeen species of Crataegus are recorded in Flora Reipublicae Popularis Sinicae (FRPS). A great deal of attention has recently been paid to Crataegus pinnatifida Bge and varieties of Shanlihong (Crataegus pinnatifida Bge. var. major N.E.Br.), Crataegus brettschneideri (Fu hawthorn) and Crataegus scabrifolia (Yun nan hawthorn) in China [1]. However, Crataegus songorica (CS), Crataegus altaica (CA) and Crataegus kansuensis (CK) have hardly any reports. Crataegi folium have been widely applied for medicinal and food materials in China and European countries [2]. Their leaves play an important role in improving digestion [3], promoting blood circulation [4,5], immune functions [6] and sugar and lipid metabolism [7] in China for a long period. Some flavonoids compounds such as vitexin-2"-O-glucoside, vitexin-2"-O-rhamnoside, vitexin, rutin, hyperoside, isoquercitrin, quercetin and epicatechinin have been isolated from the leaves of Crataegus pinnatifida [8-10] as the main active 
compounds, which exhibited a wide range of pharmacological activities including cardiovascular diseases [11-13], antihypertensive [14] and anti-inflammatory [15], free radical scavenging [16], exercise tolerance and improved the symptoms of fatigue and breathing shortness $[5,17]$. In the recent study, these flavonoids compounds are analyzed by a high-performance liquid chromatographic (HPLC) $[9,18,19]$, capillary zone electrophoresis (CZE) method [20], high-speed counter-current chromatography (HSCCC) [21] and ultra-performance liquid chromatography electrospray ionization tandem mass spectrometric (UPLC-ESI-MS) methods [22], which have been carried out the pharmacokinetics of vitexin-2"-O-rhamnoside and vitexin-4"-O-glucoside that expressed they were effective compounds.

CS, CA and CK are primarily three hawthorn species in Xinjiang (China) [23], previous literature mostly focused on ornamental tree species and rootstocks and breeding materials for cultivated hawthorn. However, there are no reports of quantitative and qualitative analysis of flavonoids compounds in their leaves. Therefore, the study aimed to develop a quantitative and qualitative method based on LC-MS/MS for simultaneous determination of 8 flavonoids compounds (rutin, quercetin, hyperoside, isoquercetin, vitexin-2"-O-glucoside, vitexin-2"-O-rhamnoside, vitexin and epicatechin) from different harvesting periods of the leaves of CS, CA and CK. Furthermore, similarities and differences of the 8 flavonoids compounds between different species and harvesting periods were clarified according to the principal component analysis (PCA) and orthogonal projections to latent structures discriminant analysis (OPLS-DA). Collectively, our study laid the foundation for the comprehensive utilization and subsequent research of the leaves of CS, CA and CK.

\section{Results and Discussion}

\subsection{The Results of Qualitative Analysis}

\subsubsection{Identification of Unique Compounds in Three Species of Crataegi folium}

Chemspider and Progenesis Metascope (SDF) databases were used to identify unknown compounds. Additionally, rutin, quercetin, hyperoside, isoquercetin, vitexin-2"$\mathrm{O}$-glucoside, vitexin-2"-O-rhamnoside, vitexin and epicatechin as a reference were determined. According to the high score, high fragmentation score and mass error $\leq 5 \mathrm{ppm}$, just a few compounds had a mass error of $5-10 \mathrm{ppm}$ and adducts $\left([\mathrm{M}-\mathrm{H}]^{-},\left[\mathrm{M}-\mathrm{H}_{2} \mathrm{O}-\mathrm{H}\right]^{-}\right.$and $[\mathrm{M}+\mathrm{FA}-\mathrm{H}]^{-}$) were screened, and 216 compounds in total were identified in the leaves of CS, CA and CK in Table S1, and among them, there were 97 flavonoids, 13 triterpenoids, 31 phenylpropanoids and so on. Based on the Progenesis QI statistical analysis had a fold range of $\geq 2$ and analysis of variance (ANOVA) $p$-value of $\leq 0.05$ and VIP in S-plot of $\geq 1$. A maximum false discovery rate (FDR)-adjusted $q$ value threshold of 0.01 was used for unique compounds.

The PCA and OPLS-DA plot of 216 identified compounds in the leaves of CS, CA and CK were fitted by EZInfo 3.0. Besides, $R^{2} X$ and $Q^{2}$ (cum) were usually used to evaluate the quality of the PCA model, both $R^{2} X$ and $Q^{2}$ (cum) were higher, the quality of the PCA model was better. The $\mathrm{R}^{2} \mathrm{X}$ and $\mathrm{Q}^{2}$ of the PCA model of CS, CK and CA were 0.990 and 0.956 respectively, which showed the PCA model fit well. As shown in Figure 1A, the QC sample formed a tight cluster, proving the reliability of the acquired data, CA and CK were separated from CS. To look for unique compounds, OPLS-DA was generated, and $R^{2} X$, $R^{2} Y$, and $Q^{2}$ (cum) were mostly used to estimate the quality of the OPLS-DA model. Both $R^{2} X, R^{2} Y$ and $Q^{2}$ (cum) were higher, the OPLS-DA model was better. Moreover, as for the OPLS-DA model of CS versus CA, $R^{2} X, R^{2} Y$ and $Q^{2}$ were $0.911,0.989$ and 0.988 , and CS versus $C K$ were $0.907,0.995$ and 0.994 respectively that showed these models with fit good. As shown in Figure 1B,C, either CS versus CA or CS versus CK was apart well, which expressed they had a remarkable difference. 

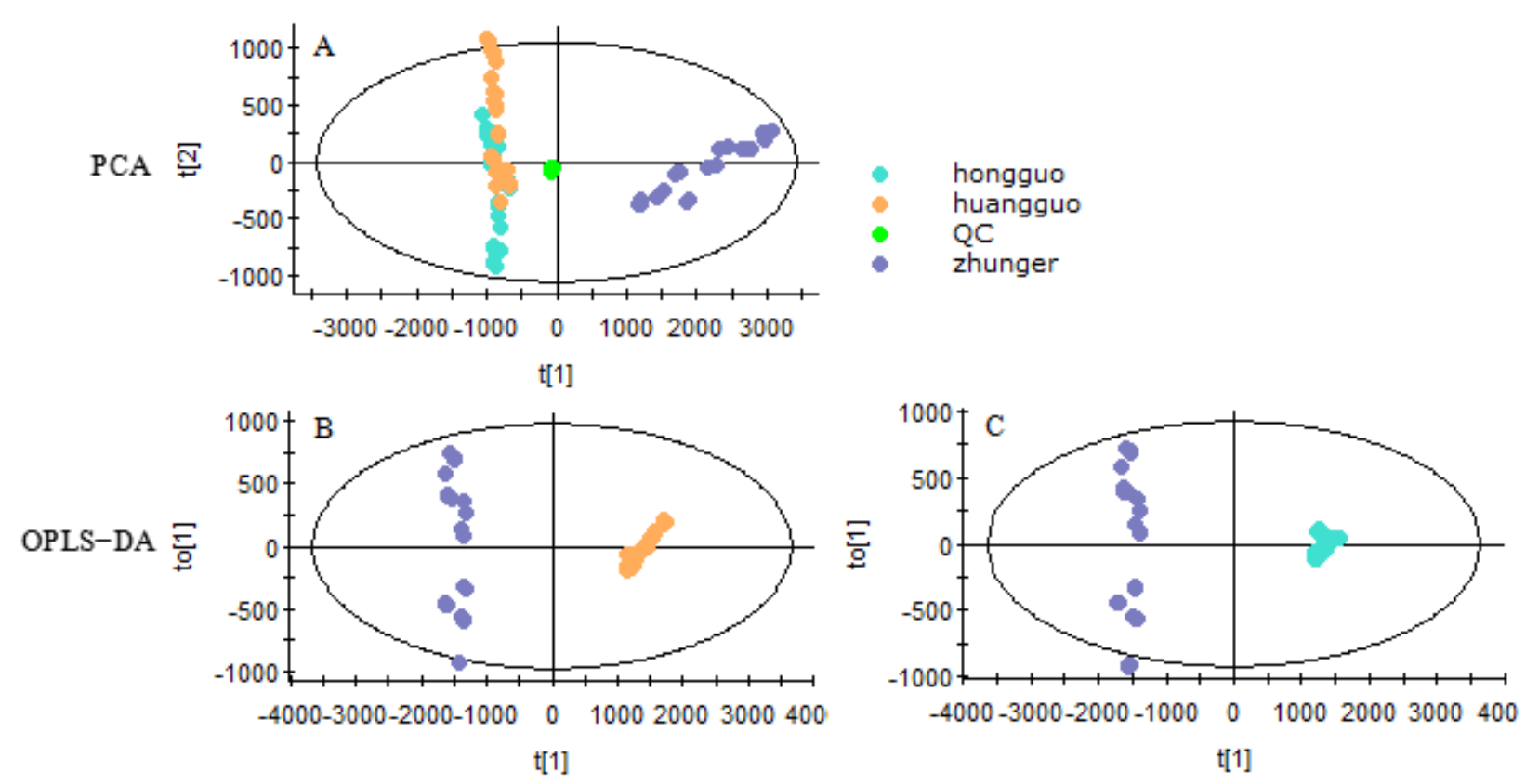

Figure 1. The statistical analysis of identified compounds of the score plot from principal component analysis (PCA) (A) and orthogonal projections to latent structures discriminant analysis (OPLS-DA) model with Hotelling's 95\% confidence ellipse from Crataegi folium of Crataegus songorica (CS) (zhunger) vs. Crataegus altaica (CA) (huanggguo) (B) and CS vs. Crataegus kansuensis (CK) (hongguo) (C).

To relate the compound and different species the scatter plot (S-plot) and variable importance plot (VIP) were used to confidence intervals from the OPLS-DA model. The S-plot shows a graphical interpretation of the covariance and the correlation between the loading variables and the predictive score $t[1,24]$. The $p[1]$ axis defines the magnitude of each variable in $\mathrm{X}$, while the $p$ (corr) [1] axis represents the reliability of each variable in $\mathrm{X}$, thus, the $X$-variables farthest from the origin combine high influence with high reliability in the model [25] and the further a marker is from the origin, the greater it is their contribution to the variance between these groups [26]. Taking CS versus CK as an example, an S-Plot of OPLS-DA was fitted, and the compounds of VIP $\geq 1$ were picked, which was revealed in the red box in Figure 2, 28 unique compounds were screened in Table 1.

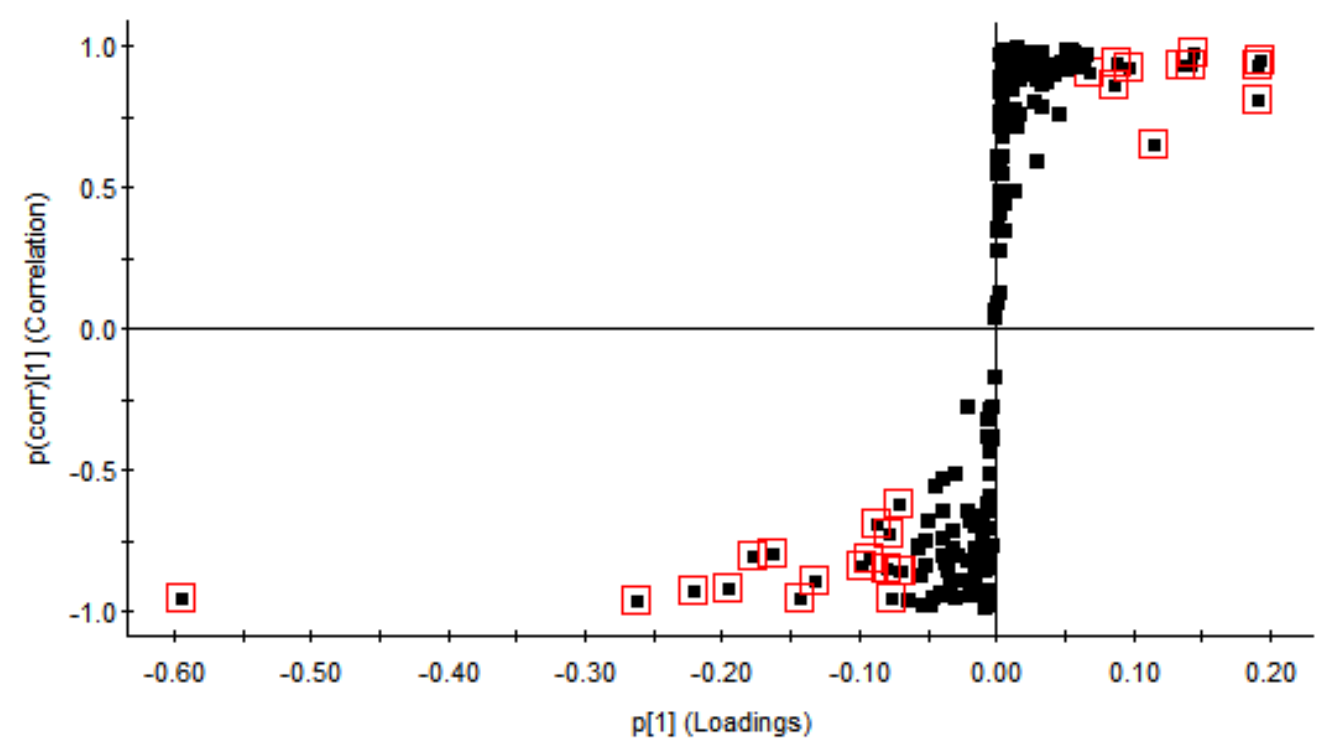

Figure 2. The S-plot of identified compounds from OPLS-DA of CS vs. CK, labeled with a variable importance plot (VIP) $>1$. 
Table 1. Identification of the unique compound selected VIP > 1 from S-plot compared CS with CK.

\begin{tabular}{|c|c|c|c|c|c|c|c|}
\hline NO & Compound & $\begin{array}{c}\mathrm{RT} \\
(\mathrm{min})\end{array}$ & Adducts & Formula & Fragmentation Ions & $\begin{array}{l}\text { Mass Error } \\
\quad(\mathrm{ppm})\end{array}$ & $m / z$ \\
\hline 1 & $\alpha$-D-Gal-( $\rightarrow 3)-\alpha$-D-Gal-OMe & 0.64 & $\mathrm{M}-\mathrm{H}_{2} \mathrm{O}-\mathrm{H}$ & $\mathrm{C}_{13} \mathrm{H}_{24} \mathrm{O}_{11}$ & $\begin{array}{l}\text { 309(13), 191(100), 137(12), } \\
125(7)\end{array}$ & -2.53 & 337.1131 \\
\hline 2 & $\begin{array}{l}\text { (2S)-Hex-2-ulofuranosyl-4,6- } \\
\text { dideoxyhexopyranoside }\end{array}$ & 0.96 & M-H & $\mathrm{C}_{12} \mathrm{H}_{22} \mathrm{O}_{9}$ & $\begin{array}{c}309(100), 179(62), 129(97) \\
119(54), 89(53)\end{array}$ & 2.92 & 309.1200 \\
\hline 3 & Glucogallin & 1.24 & M-H & $\mathrm{C}_{13} \mathrm{H}_{16} \mathrm{O}_{10}$ & $\begin{array}{c}331(89), 168(49), 149(100) \\
125(61), 107(1)\end{array}$ & 6.54 & 331.0692 \\
\hline 4 & Eucomic acid & 2.50 & $\mathrm{M}+\mathrm{FA}-\mathrm{H}$ & $\mathrm{C}_{11} \mathrm{H}_{12} \mathrm{O}_{6}$ & $\begin{array}{l}\text { 285(80), 208(13), 152(52), } \\
121(1), 108(100)\end{array}$ & 3.75 & 285.0625 \\
\hline 5 & $\begin{array}{c}\text { 2-succinyl-6-hydroxycyclohexa-2,4- } \\
\text { diene-1-carboxylic } \\
\text { acid }\end{array}$ & 4.01 & M-H & $\mathrm{C}_{11} \mathrm{H}_{12} \mathrm{O}_{6}$ & $\begin{array}{c}203(3), 179(7), 163(22) \\
119(100)\end{array}$ & 3.62 & 239.0573 \\
\hline 6 & $\begin{array}{c}\text { (3R,5S,6S,7E,9S)-Megastigman-7- } \\
\text { ene-3,5,6,9-tetrol-9-O- } \beta \text {-D- } \\
\text { glucopyranoside }\end{array}$ & 4.49 & $\mathrm{M}+\mathrm{FA}-\mathrm{H}$ & $\mathrm{C}_{19} \mathrm{H}_{34} \mathrm{O}_{9}$ & $\begin{array}{l}395(1), 167(28), 153(14) \\
145(100)\end{array}$ & 0.12 & 451.2185 \\
\hline 7 & Procyanidin B1 & 4.69 & M-H & $\mathrm{C}_{30} \mathrm{H}_{26} \mathrm{O}_{12}$ & $\begin{array}{l}451(10), 425(86), 407(100), \\
289(91), 245(39), 125(60)\end{array}$ & -3.90 & 577.1354 \\
\hline 8 & Chlorogenic acid & 5.52 & M-H & $\mathrm{C}_{16} \mathrm{H}_{18} \mathrm{O}_{9}$ & $\begin{array}{c}289(100), 205(18), 191(88) \\
123(51), 109(54)\end{array}$ & 2.39 & 353.0887 \\
\hline 9 & Procyanidin C1 & 7.00 & M-H & $\mathrm{C}_{45} \mathrm{H}_{38} \mathrm{O}_{18}$ & $\begin{array}{c}695(15), 577(23), 451(23) \\
289(99), 125(66)\end{array}$ & 4.79 & 865.2027 \\
\hline 10 & $\begin{array}{l}\text { (Z)-3-Hexenyl-O- } \beta \text {-D- } \\
\text { xylopyranosyl- }\left(1^{\prime \prime} \rightarrow 6^{\prime}\right)-\beta \text {-D- } \\
\text { glucopyranoside }\end{array}$ & 8.02 & $\mathrm{M}+\mathrm{FA}-\mathrm{H}$ & $\mathrm{C}_{17} \mathrm{H}_{30} \mathrm{O}_{10}$ & $\begin{array}{l}\text { 221(1), 172(100), 131(2) } \\
101(27), 89(8)\end{array}$ & 0.27 & 439.1822 \\
\hline 11 & 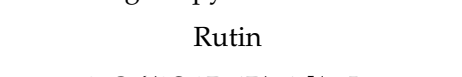 & 8.88 & M-H & $\mathrm{C}_{27} \mathrm{H}_{30} \mathrm{O}_{16}$ & $\begin{array}{l}\text { 563(8), 463(9), 446(81), } \\
\text { 299(100), 271(10) }\end{array}$ & 0.94 & 609.1467 \\
\hline 12 & $\begin{array}{c}\text { 2-O-\{(2S,3R,4R)-4-[( } \alpha \text {-L- } \\
\text { arabinopyranosyloxy)methyl]-3,4- } \\
\text { dihydroxytetrahydro-2-furanyl }\}-\beta- \\
\text { D-galactopyranoside }\end{array}$ & 9.15 & $\mathrm{M}-\mathrm{H}_{2} \mathrm{O}-\mathrm{H}$ & $\mathrm{C}_{32} \mathrm{H}_{38} \mathrm{O}_{21}$ & $\begin{array}{c}739(100), 579(10), 569(30) \\
307(3)\end{array}$ & -5.18 & 739.1688 \\
\hline 13 & 7-O-rhamnogalactoside quercetin & 9.48 & $\mathrm{M}-\mathrm{H}$ & $\mathrm{C}_{27} \mathrm{H}_{30} \mathrm{O}_{16}$ & $\begin{array}{c}300(100), 271(17), 255(6) \\
243(1)\end{array}$ & 0.42 & 609.1464 \\
\hline 14 & 6-C-glucoside-8-C-xylsoyl apigenin & 10.00 & $\mathrm{M}+\mathrm{FA}-\mathrm{H}$ & $\mathrm{C}_{26} \mathrm{H}_{28} \mathrm{O}_{14}$ & $\begin{array}{c}500(6), 446(60), 251(100) \\
117(82), 89(3)\end{array}$ & 1.36 & 609.1469 \\
\hline 15 & vitexin-2"-O-rhamnoside & 10.68 & $\mathrm{M}-\mathrm{H}$ & $\mathrm{C}_{27} \mathrm{H}_{30} \mathrm{O}_{14}$ & $\begin{array}{l}\text { 413(20), 341(1), 311(4), } \\
293(100), 269(1), 173(1)\end{array}$ & 0.30 & 577.1565 \\
\hline 16 & vitexin & 10.70 & $\mathrm{M}-\mathrm{H}_{2} \mathrm{O}-\mathrm{H}$ & $\mathrm{C}_{21} \mathrm{H}_{20} \mathrm{O}_{10}$ & $\begin{array}{c}341(1), 311(8), 293(100) \\
269(1), 117(1)\end{array}$ & 4.34 & 413.0897 \\
\hline 17 & Vitexin-2"-O-glucoside & 10.72 & $\mathrm{M}-\mathrm{H}$ & $\mathrm{C}_{27} \mathrm{H}_{30} \mathrm{O}_{15}$ & $\begin{array}{l}577(44), 413(19), 341(1) \\
311(8), 293(100), 117(1)\end{array}$ & 0.66 & 593.1516 \\
\hline 18 & $\begin{array}{c}\text { 3-O- } \beta-D-6 " \text {-acetylglucopyranoside } \\
\text { quercetin }\end{array}$ & 12.10 & $\mathrm{M}-\mathrm{H}$ & $\mathrm{C}_{23} \mathrm{H}_{22} \mathrm{O}_{13}$ & $\begin{array}{c}463(1), 300(100), 271(51) \\
255(23), 243(6), 151(5) \\
473(86), 413(23), 341(9)\end{array}$ & 0.86 & 505.0992 \\
\hline 19 & Vitexin-3"-O-acetyl & 13.04 & $\mathrm{M}-\mathrm{H}$ & $\mathrm{C}_{23} \mathrm{H}_{22} \mathrm{O}_{11}$ & $\begin{array}{c}311(96), 283(100), 161(9) \\
117(6)\end{array}$ & 1.01 & 473.1094 \\
\hline 20 & Picroside III & 14.49 & M-H & $\mathrm{C}_{25} \mathrm{H}_{30} \mathrm{O}_{13}$ & $\begin{array}{c}\text { 462(2), 431(9), 316(1), } \\
\text { 181(9), 153(100), 136(1) }\end{array}$ & -2.14 & 583.1674 \\
\hline 21 & Vitexin-6"-O-acetyl & 15.53 & $\mathrm{M}-\mathrm{H}$ & $\mathrm{C}_{23} \mathrm{H}_{22} \mathrm{O}_{11}$ & $\begin{array}{l}\text { 413(27), 311(68), 283(100), } \\
268(4)\end{array}$ & 2.62 & 473.1102 \\
\hline 22 & Linalyl rutinoside & 16.43 & $\mathrm{M}-\mathrm{H}$ & $\mathrm{C}_{22} \mathrm{H}_{38} \mathrm{O}_{10}$ & $\begin{array}{c}\text { 413(26), 371(5), 211(7) } \\
\text { 197(7), 145(100) }\end{array}$ & 0.07 & 461.2393 \\
\hline 23 & Madecassic acid & 18.31 & $\mathrm{M}-\mathrm{H}$ & $\mathrm{C}_{30} \mathrm{H}_{48} \mathrm{O}_{6}$ & $\begin{array}{c}\text { 503(100), } 485(17), 441(23), \\
235(1)\end{array}$ & -0.73 & 549.3435 \\
\hline 24 & $2 \alpha, 3 \beta, 19 \alpha$-thihydroxyl ursolic acid & 19.14 & $\mathrm{M}-\mathrm{H}$ & $\mathrm{C}_{30} \mathrm{H}_{48} \mathrm{O}_{5}$ & $\begin{array}{c}487(100), 469(8), 443(1) \\
423(1)\end{array}$ & 0.07 & 487.3429 \\
\hline 25 & 3-O-t-p-Coumaroyltormentic acid & 19.60 & $\mathrm{M}-\mathrm{H}$ & $\mathrm{C}_{39} \mathrm{H}_{54} \mathrm{O}_{7}$ & $\begin{array}{c}\text { 633(100), 589(1),145(7) } \\
119(1)\end{array}$ & 2.22 & 679.3878 \\
\hline 26 & $\begin{array}{c}(2 \alpha, 3 \beta)-2,19-\text { Dihydroxy-3-\{[(2Z)-3- } \\
\text { (4-hydroxyphenyl)-2- } \\
\text { propenoyl]oxy\}urs-12-en-28-oic } \\
\text { acid }\end{array}$ & 19.81 & $\mathrm{M}+\mathrm{FA}-\mathrm{H}$ & $\mathrm{C}_{39} \mathrm{H}_{54} \mathrm{O}_{7}$ & $\begin{array}{c}\text { 633(100), 589(2),513(1) } \\
145(16), 119(1)\end{array}$ & 2.98 & 679.3871 \\
\hline 27 & $\begin{array}{c}\text { Jacoumaric acid } \\
(3 \beta, 5 \xi, 9 \xi, 14 \beta)-3-H y d r o x y-27-\end{array}$ & 20.03 & $\mathrm{M}-\mathrm{H}$ & $\mathrm{C}_{39} \mathrm{H}_{54} \mathrm{O}_{6}$ & $617(100), 497(4), 472(49)$ & -1.09 & 617.3841 \\
\hline 28 & $\begin{array}{c}\{[(2 E)-3-(4-h y d r o x y p h e n y l)-2- \\
\text { propenoyl]oxy\}urs-12-en-28-oic } \\
\text { acid }\end{array}$ & 20.30 & $\mathrm{M}-\mathrm{H}$ & $\mathrm{C}_{39} \mathrm{H}_{54} \mathrm{O}_{6}$ & $\begin{array}{l}\text { 617(100),573(1), 497(2), } \\
453(1), 145(22), 117(2)\end{array}$ & 1.56 & 617.3857 \\
\hline
\end{tabular}


Normalized abundances were used to calculate relative content of 28 unique compounds in Figure S2. Among them, rutin, 6-C-glucoside- $8-C$-xylsoyl apigenin, vitexin6"-O-acetyl, vitexin, vitexin-2"-O-glucoside, vitexin-3"-O-acetyl, 7-O-rhamnogalactoside quercetin vitexin-2"-O-rhamnoside and so on were reported in Crataegus pinnatifida Bge, besides, rutin, vitexin, vitexin-2"-O-glucoside and vitexin-2"-O-rhamnoside were compared with the reference. As shown in Figure S2, compared with total content of 28 unique compounds, we found the leaves of CS were always higher than CK in different harvesting periods, and the content of vitexin-2"-O-rhamnoside was highest in the leaves of CS. Moreover, we discovered the constitution of compounds were notable difference in CS and CK, which could be used to distinguish different species of Crataegi folium. In addition, the variation trend of 28 unique compounds in different harvesting periods can be a reference to optimize harvesting periods.

\subsubsection{The Main Fragmentation Patterns of Representative Flavonoids Compounds}

There were various skeleton types of flavonoids in Crataegi folium, in this study the main types obtained were vitexin-type, quercetin-type and epicatechin-type. A strong excimer ion peak of $[\mathrm{M}-\mathrm{H}]^{-}$was acquired.

The vitexin-type were mostly from a $\mathrm{C}_{4} \mathrm{H}_{8} \mathrm{O}_{3}$ loss and generated $\left[\mathrm{M}^{-} \mathrm{C}_{4} \mathrm{H}_{8} \mathrm{O}_{3}-\mathrm{H}\right]^{-}$ $\left(\mathrm{m} / \mathrm{z}\right.$ 311.0531) in Figure 3A, and then one $\mathrm{H}_{2} \mathrm{O}$ loss and obtained $\left[\mathrm{M}-\mathrm{C}_{4} \mathrm{H}_{8} \mathrm{O}_{3}-\mathrm{H}_{2} \mathrm{O}-\mathrm{H}\right]^{-}$ $\left(\mathrm{m} / z\right.$ 293.0448), another $\mathrm{CO}$ loss and acquired $\left[\mathrm{M}-\mathrm{C}_{4} \mathrm{H}_{8} \mathrm{O}_{3}-\mathrm{CO}-\mathrm{H}\right]^{-}(\mathrm{m} / z$ 283.0588), after that, a common ion $m / z 177.0343$ was observed. Finally, a $\mathrm{C}_{8} \mathrm{H}_{5} \mathrm{O}$ loss from $m / z 293.0448$ and generated the ion $m / z$ 175.0026. Furthermore, vitexin-2"-O-rhamnoside $\left([\mathrm{M}-\mathrm{H}]^{-}, \mathrm{m} / \mathrm{z}\right.$ 577.1551) lost one rhamnose $\left(\mathrm{C}_{6} \mathrm{H}_{10} \mathrm{O}_{4}\right)$ and obtained vitexin, in the same way, vitexin-2" O-glucoside $\left([\mathrm{M}-\mathrm{H}]^{-}, m / z 593.1516\right)$ lost one glucose $\left(\mathrm{C}_{6} \mathrm{H}_{10} \mathrm{O}_{5}\right)$ and generated vitexin.

The quercetin-type were primarily from a CO loss and developed [M-CO-H] ${ }^{-}(\mathrm{m} / \mathrm{z}$ 273.0799) shown in Figure $3 \mathrm{~B}$, and then a $\mathrm{H}_{2} \mathrm{O}$ loss and obtained [M-CO- $\left.\mathrm{H}_{2} \mathrm{O}-\mathrm{H}\right]^{-}(\mathrm{m} / \mathrm{z}$ 255.0285), due to the loss of $\mathrm{CO}$, respectively, the base peak ions were [M-CO-CO- $\left.\mathrm{H}_{2} \mathrm{O}-\mathrm{H}\right]^{-}$ $\left(\mathrm{m} / \mathrm{z} \text { 227.0346) and [M-CO-CO-CO-H }{ }_{2} \mathrm{O}-\mathrm{H}\right]^{-}\left(\mathrm{m} / \mathrm{z}\right.$ 199.0434). On the other way, a $\mathrm{C}_{7} \mathrm{H}_{4} \mathrm{O}_{2}$ lost and formed [M-CO- $\left.\mathrm{C}_{7} \mathrm{H}_{4} \mathrm{O}_{2}-\mathrm{H}\right]^{-}\left(\mathrm{m} / z\right.$ 151.0024), because of the loss of one $\mathrm{H}_{2} \mathrm{O}$ or $\mathrm{CO}_{2}$, the peak ions were [M-CO- $\left.\mathrm{C}_{7} \mathrm{H}_{4} \mathrm{O}_{2}-\mathrm{H}_{2} \mathrm{O}-\mathrm{H}\right]^{-}\left(\mathrm{m} / \mathrm{z} \text { 133.0289) or [M-CO- } \mathrm{C}_{7} \mathrm{H}_{4} \mathrm{O}_{2}-\mathrm{CO}_{2}-\mathrm{H}\right]^{-}$ $\left(\mathrm{m} / \mathrm{z}\right.$ 107.0136). In addition, one rhamnose $\left(\mathrm{C}_{6} \mathrm{H}_{9} \mathrm{O}_{4}\right)$ lost from rutin $\left([\mathrm{M}-\mathrm{H}]^{-}, \mathrm{m} / z\right.$ 609.1444) and performed isoquercetin $\left([\mathrm{M}-\mathrm{H}]^{-}, m / z 463.0903\right)$, and then one glucose $\left(\mathrm{C}_{6} \mathrm{H}_{10} \mathrm{O}_{5}\right)$ lost from isoquercetin and hyperoside and conducted quercetin $\left([\mathrm{M}-\mathrm{H}]^{-}, m / z 301.0323\right)$.

As shown in Figure 3C, epicatechin-type were preeminently from a $\mathrm{H}_{2} \mathrm{O}$ loss and carried out fragment peak [ $\left.\mathrm{M}-\mathrm{H}_{2} \mathrm{O}-\mathrm{H}\right]^{-}(\mathrm{m} / \mathrm{z} 271.0567)$, resulted from the loss of $\mathrm{C}_{6} \mathrm{H}_{6} \mathrm{O}_{2}$, $\mathrm{C}_{9} \mathrm{H}_{8} \mathrm{O}_{3}$, and $\mathrm{C}_{8} \mathrm{H}_{8} \mathrm{O}_{3}$, the fragment ions were $\left[\mathrm{M}-\mathrm{C}_{6} \mathrm{H}_{6} \mathrm{O}_{2}-\mathrm{H}\right]^{-}(\mathrm{m} / z \mathrm{z} 179.0326)$, [ $\left[\mathrm{M}-\mathrm{C}_{9} \mathrm{H}_{8} \mathrm{O}_{3}\right.$ $\mathrm{H}^{-}\left(\mathrm{m} / \mathrm{z} \text { 125.0226) and [M- } \mathrm{C}_{8} \mathrm{H}_{8} \mathrm{O}_{3}-\mathrm{H}\right]^{-}(\mathrm{m} / \mathrm{z}$ 137.0221), independently. Subsequently, with one CO loss, $\left[\mathrm{M}-\mathrm{C}_{6} \mathrm{H}_{6} \mathrm{O}_{2}-\mathrm{CO}-\mathrm{H}\right]^{-}(\mathrm{m} / z$ 151.0376) was generated. According to the loss of $\mathrm{CO}$ and $\mathrm{H}_{2} \mathrm{O}$ step by step, a series of fragment peaks [M- $\left.\mathrm{C}_{8} \mathrm{H}_{8} \mathrm{O}_{3}-\mathrm{CO}-\mathrm{H}\right]^{-}(\mathrm{m} / z$ 109.0293) and $\left[\mathrm{M}-\mathrm{C}_{8} \mathrm{H}_{8} \mathrm{O}_{3}-\mathrm{CO}-\mathrm{H}_{2} \mathrm{O}-\mathrm{H}\right]^{-}(\mathrm{m} / \mathrm{z}$ 91.0184) originated. 
A

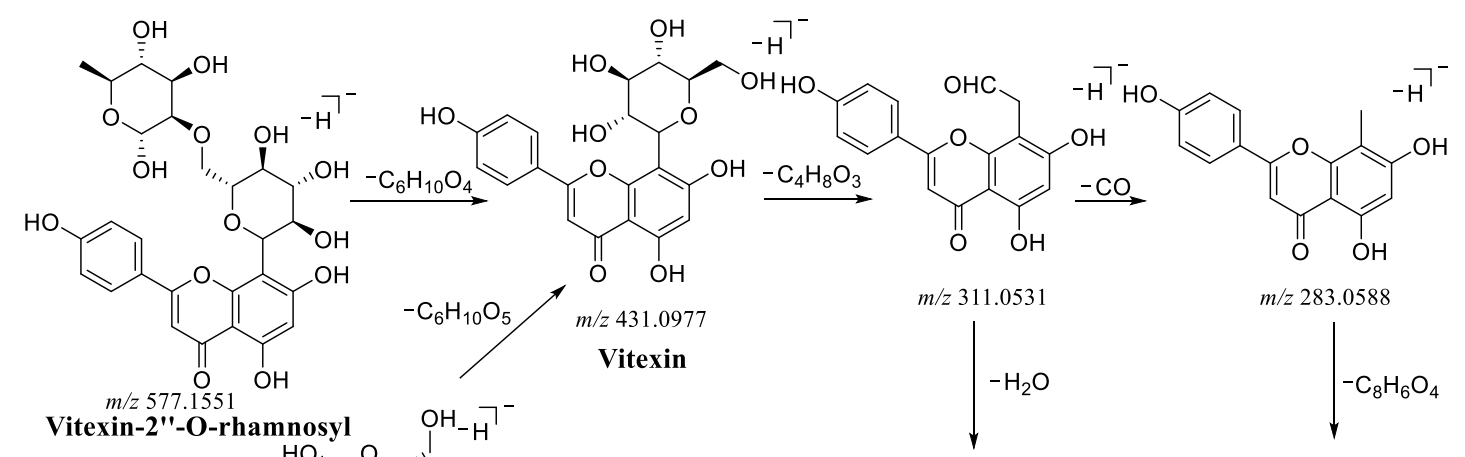

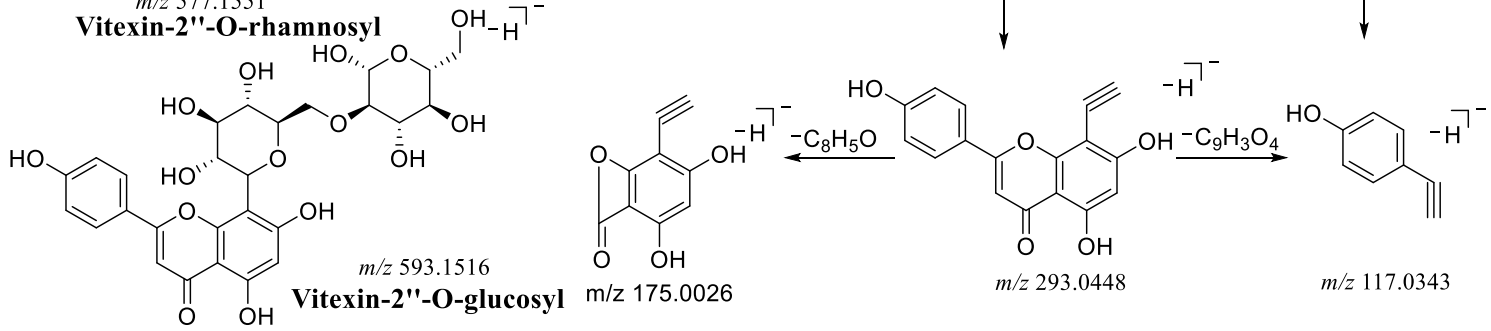

B

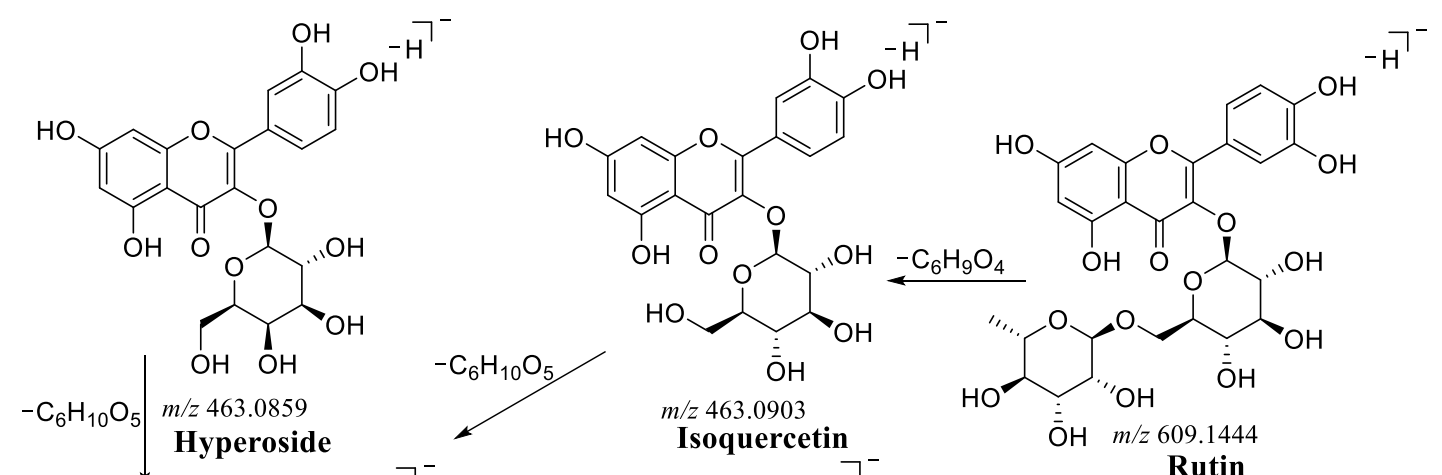

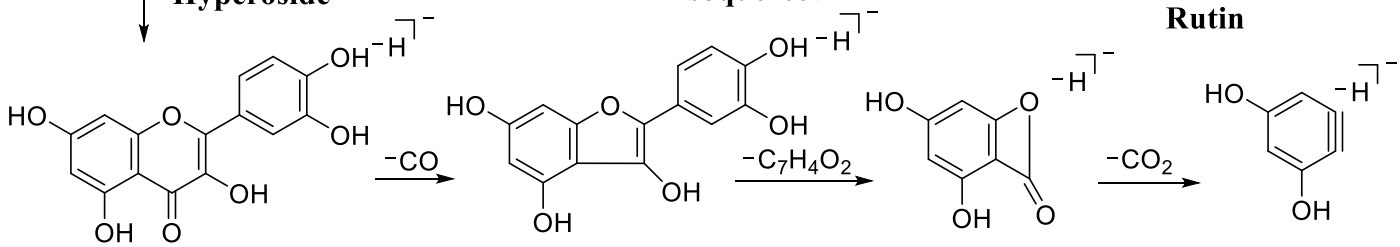

$\mathrm{m} / \mathrm{z} 301.0323$

Quercetin<smiles>O=C([O-])COc1cc(C2=C3C=CC=C3O2)ccc1O</smiles>

$m / z 199.0434$<smiles></smiles>

$m / z 227.0346$

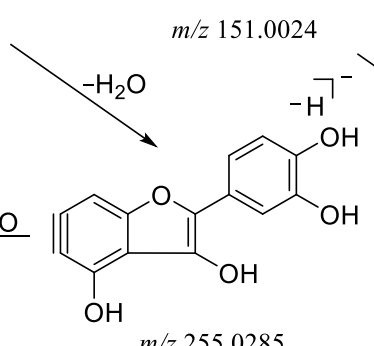

$m / z 255.0285$ $m / z 107.0136$<smiles>O=c1oc2ccc(O)cc2o1</smiles>

$m / z 133.0289$

Figure 3. Cont. 
C

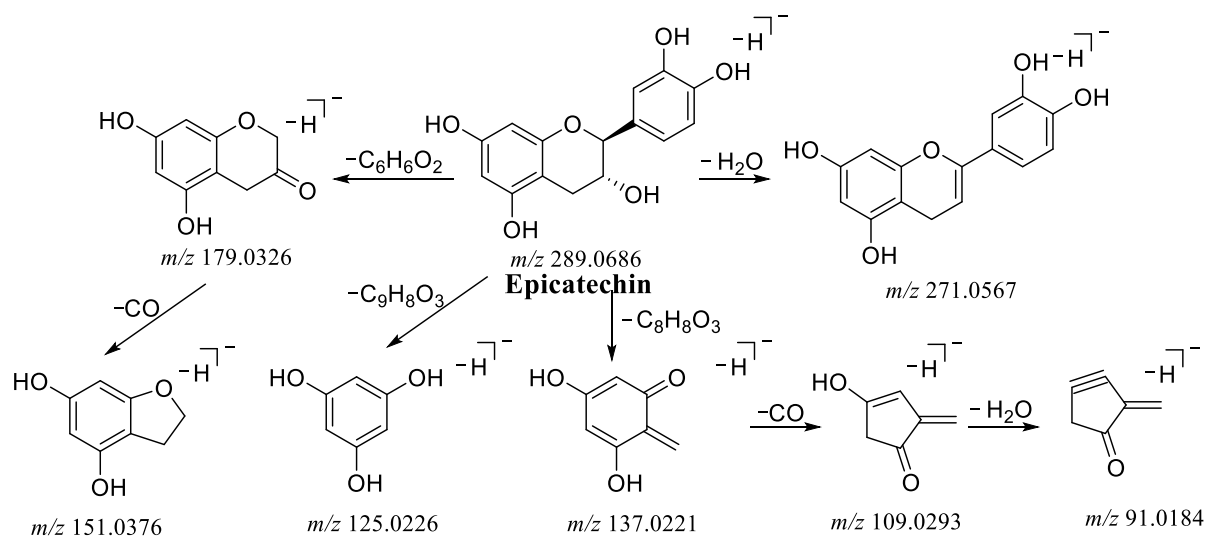

Figure 3. Mass spectrograms of representative flavonoids of different types. (A) Vitexin-type flavonoids, (B) Quercetin-type flavonoids and (C) Epicatechin-type flavonoids.

\subsection{The Results of the Quantitative Analysis}

\subsubsection{Validated Method Data}

UPLC-MS/MS chromatograms of eight flavonoids of the leaves in CS were shown in Figure 4. Mixed standards were prepared in concentrations ranging from 0.001 to $5 \mu \mathrm{g} / \mathrm{mL}$. Standard curves were carried out with coefficients of determination $(r)$ higher than 0.999 . The accuracy, repeatability, and recovery were calculated from the mean and relative standard deviation (RSD) of six replicates, the RSD of accuracy was at the range from 1.26 to $1.99 \%$, and the repeatability was $1.41-3.78 \%$. The recoveries were at the range of $95-105 \%$, the mean recoveries at $98.1-100.9 \%$. The detailed results were shown in Table 2. The validated quantitative method was supposed that is appropriate for the determination of the eight flavonoids standards of the leaves of different harvesting period of CS, CA and CK.

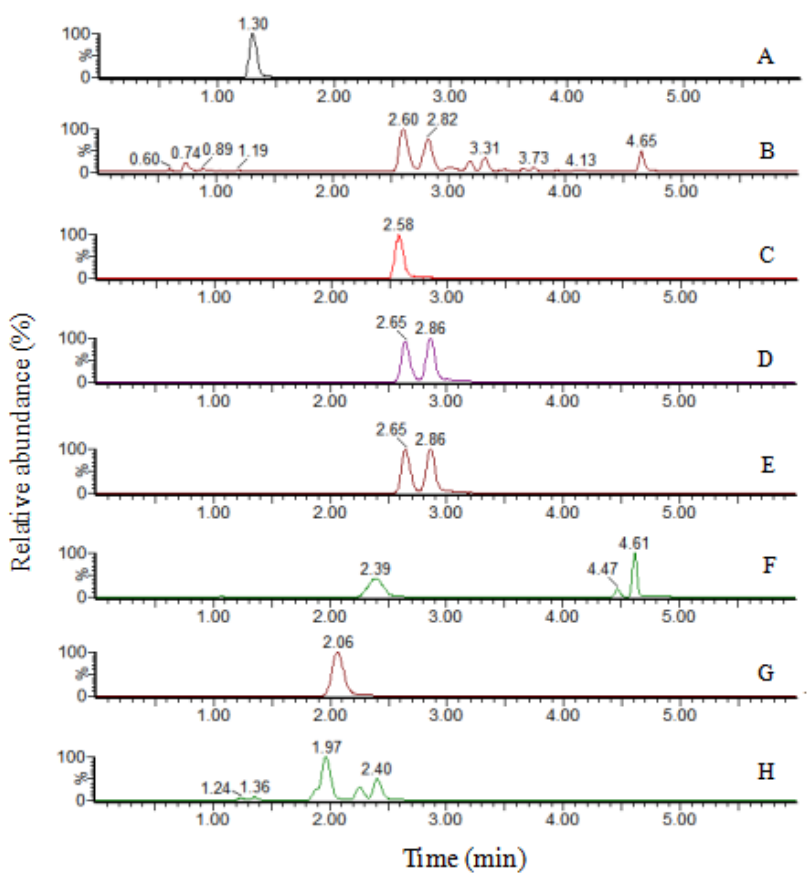

Figure 4. UPLC-MS/MS chromatograms of eight flavonoids of the leaves in CS. (A) epicatechin (1.30 $\mathrm{min})$; (B) quercetin (4.65 $\mathrm{min})$; (C) vitexin (2.58 $\mathrm{min})$; (D) isoquercetin (2.86 $\mathrm{min})$; (E) hyperoside (2.65 min); (F) vitexin-2"-O-rhamnoside (2.39 min); (G) vitexin-2"-O-glucoside (2.06 min) and (H) rutin $(2.40 \mathrm{~min})$. 
Table 2. Method validated data of the detected compounds.

\begin{tabular}{|c|c|c|c|c|c|c|c|c|c|}
\hline \multirow{2}{*}{ Analytes } & \multirow{2}{*}{ Calibration Curves } & \multirow{2}{*}{$\mathbf{r}$} & \multirow{2}{*}{$\begin{array}{l}\text { Linear Range } \\
(\mu \mathrm{g} / \mathrm{g})\end{array}$} & \multirow{2}{*}{$\begin{array}{c}\text { Accuracy ( } n \\
=6) \\
\text { RSD } \%\end{array}$} & \multirow{2}{*}{$\begin{array}{c}\text { Repeatability } \\
(n=6) \\
\text { RSD } \%\end{array}$} & \multicolumn{2}{|c|}{ Recovery $(n=6)$} & \multirow{2}{*}{$\begin{array}{l}\text { LOD } \\
(\mu \mathrm{g} / \mathrm{g})\end{array}$} & \multirow{2}{*}{$\begin{array}{c}\text { LOQ } \\
(\mu \mathrm{g} / \mathrm{g})\end{array}$} \\
\hline & & & & & & Mean & RSD $\%$ & & \\
\hline Epicatechin & $y=9.79038 x+2.87783$ & 0.9998 & $0.50-500$ & 1.88 & 2.07 & 99.9 & 2.21 & 0.10 & 0.25 \\
\hline Quercetin & $y=42.0891 x+107.983$ & 0.9990 & $0.10-100$ & 1.96 & 1.83 & 100.9 & 1.71 & 0.05 & 0.10 \\
\hline Vitexin & $y=37.7813 x-29.4584$ & 0.9997 & $0.50-500$ & 1.30 & 3.78 & 99.4 & 3.17 & 0.25 & 0.50 \\
\hline Isoquercetin & $y=12.0094 x-36.7965$ & 0.9997 & $0.50-500$ & 1.99 & 3.73 & 99.4 & 3.56 & 0.25 & 0.50 \\
\hline \multirow{2}{*}{$\begin{array}{l}\text { Hyperoside } \\
\text { vitexin-2"-O- } \\
\text { rhamnoside }\end{array}$} & $y=23.6934 x-14.5733$ & 0.9991 & $0.50-500$ & 1.65 & 1.59 & 98.3 & 3.66 & 0.25 & 0.50 \\
\hline & $y=25.0249 x-91.4384$ & 0.9997 & $0.50-500$ & 1.26 & 1.51 & 98.1 & 2.43 & 0.25 & 0.50 \\
\hline $\begin{array}{l}\text { Vitexin-2"-O- } \\
\text { glucoside }\end{array}$ & $y=22.8099 x-59.7038$ & 0.9991 & $0.50-500$ & 1.69 & 3.06 & 100.5 & 3.06 & 0.10 & 0.25 \\
\hline Rutin & $y=24.1448 x-28.9144$ & 0.9997 & $0.25-500$ & 1.87 & 1.41 & 100.4 & 1.53 & 0.10 & 0.25 \\
\hline
\end{tabular}

2.2.2. The Content of Eight Flavonoids Compounds in Different Species of Crataegi folium

The detailed content of eight flavonoids compounds of the leaves of CS, CA and CK were shown in Table S2, to elucidate the variation tendency of eight flavonoids compounds in different species, their stack columns were generated in Figure 5. We found all eight flavonoids compounds could be detected in the leaves of CS, CA and CK. Furthermore, vitexin-2"-O-rhamnoside, hyperoside, isoquercetin and epicatechin in the leaves of CS were the main contribution compounds, and most of them, the content of vitexin-2"-Orhamnoside was the highest (6.0-8.2 $\mathrm{mg} / \mathrm{g}$ ) (Table S2), which was a main active compound in Crataegus pinnatifida Bge. In addition, it is worth noting that vitexin-2"-O-rhamnoside had a higher content in CS than CA and CK in Figure 5B.

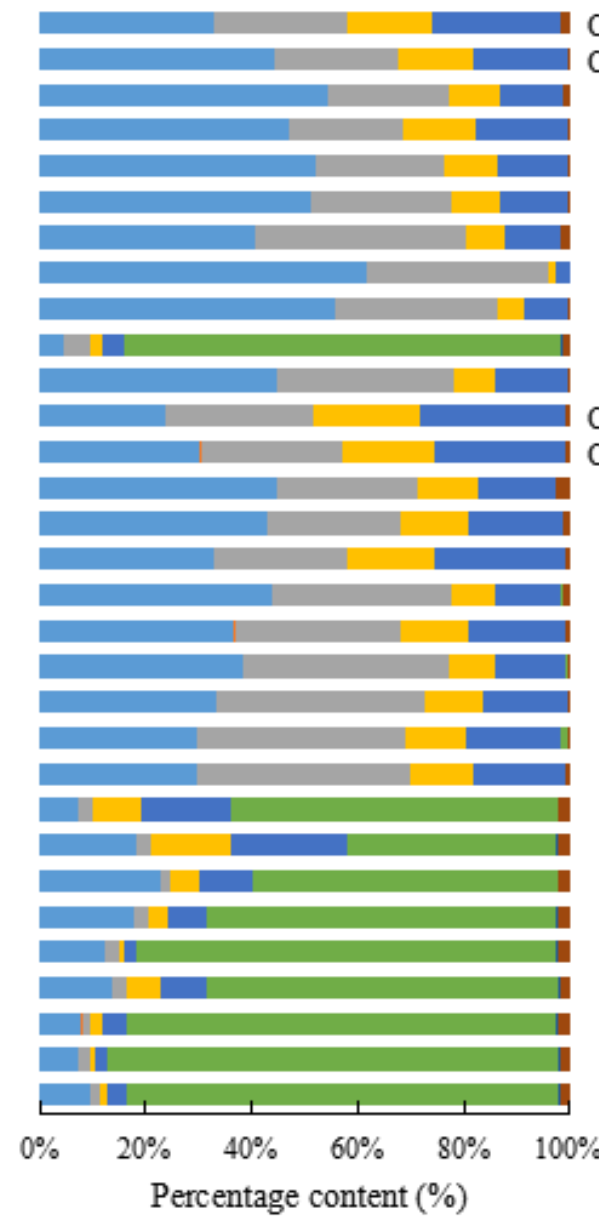

(A)

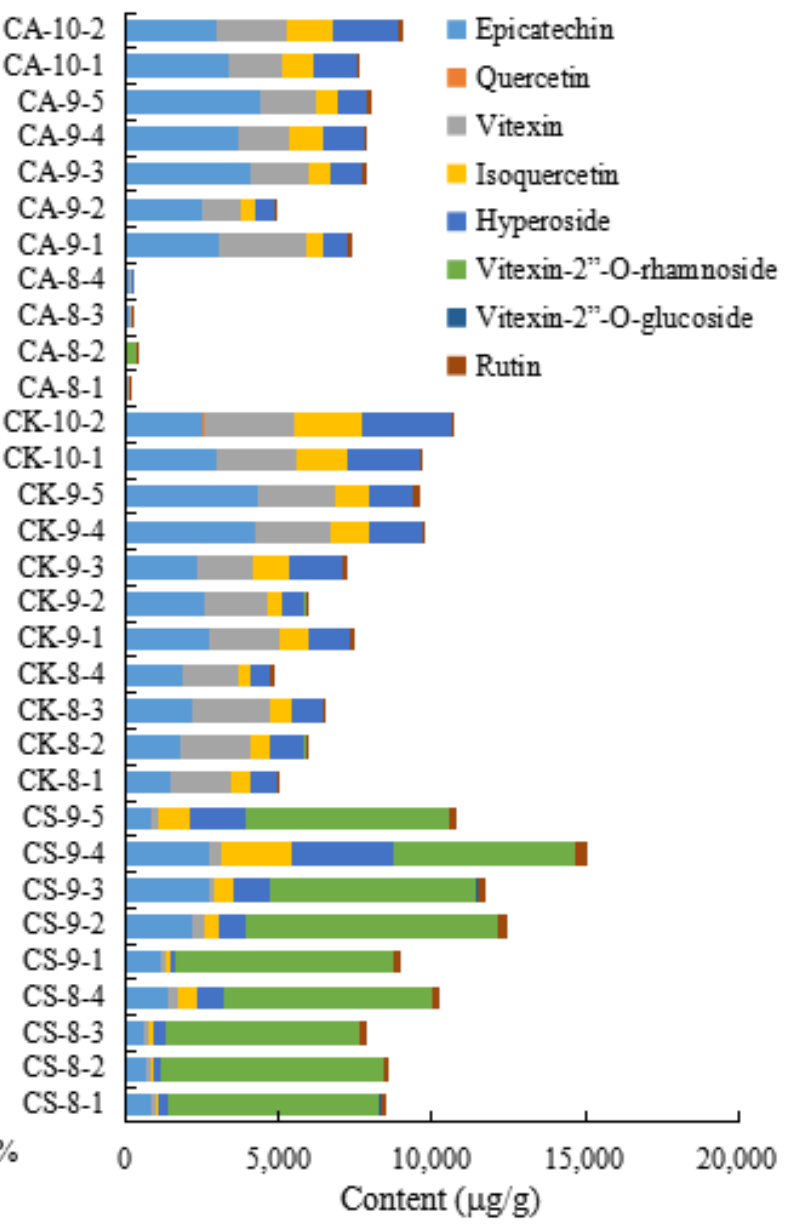

(B)

Figure 5. The content of eight flavonoids compounds of leaves of CS, CA and CK. (A) Percentage stacked column of eight flavonoids compounds. (B) Stacked column of eight flavonoids compounds. 
Additionally, the content of hyperoside, isoquercetin, vitexin and epicatechin was higher than that of the other flavonoids in the leaves of CK, but vitexin-2"-O-glucoside was not detected at all. Interestingly, the varied trend of hyperoside, isoquercetin, vitexin and epicatechin presented an analogical trend in the leaves of CA as shown in Figure 5A. These results expressed that there is a similarity between CA and CK to a certain degree.

To elucidate the distribution characteristics in different species and further look for more available resources, the PCA was applied to illustrate the correlations between the contents of flavonoids compounds of different species of hawthorn leaves. The $\mathrm{R}^{2} \mathrm{X}$ and $\mathrm{Q}^{2}$ of the PCA model of CS, CK and CA were 0.971 and 0.840 separately, which performed the PCA model fit good. The closer the two species lie on the plot, the more similar they are in the content of flavonoids compounds. On the contrary, a species that is distant from the others can have significantly different content of compounds. The triplicate LC-MS/MS analyses of each sample are overlaid on the plot, indicating good repeatability of the chemical analysis. As shown in Figure 6A, according to the PCA plot, the samples could be divided into two groups, CK and CA were grouped in the same cluster, and CS were separated from CK and CA that indicated the leaves of CS had a remarkable difference with $\mathrm{CK}$ and CA.
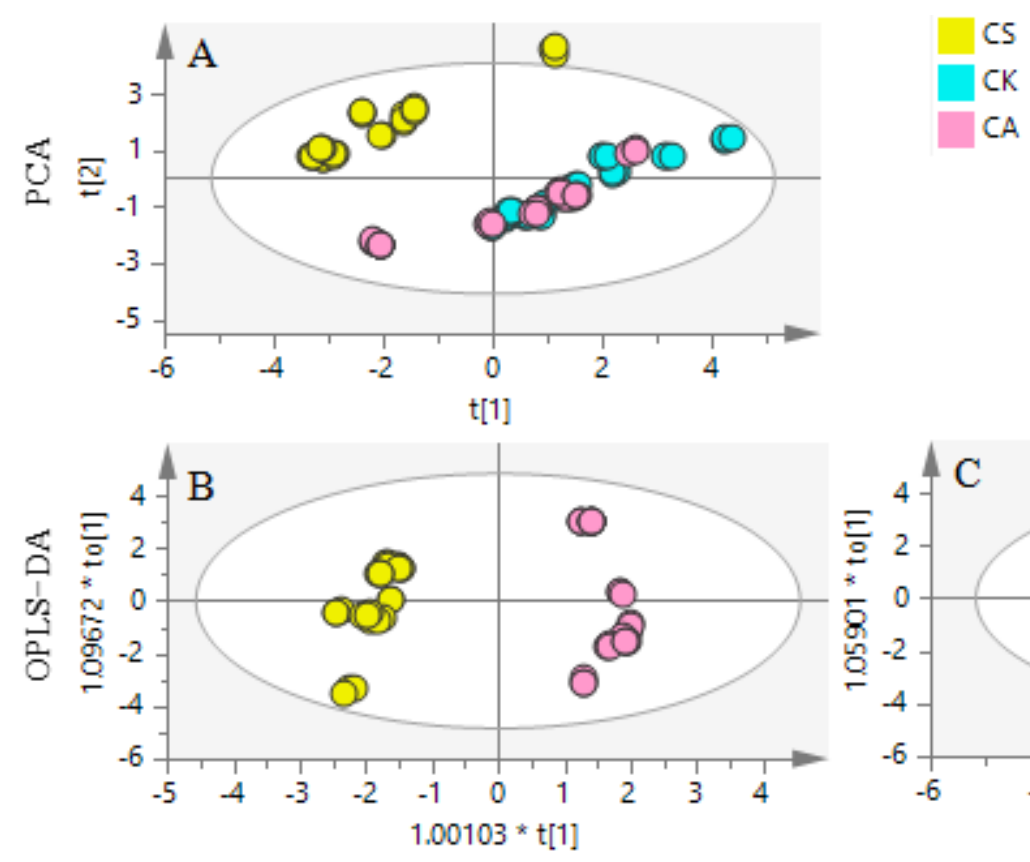

Figure 6. The statistical analysis of the content of eight flavonoids compounds score plot from PCA and OPLS-DA model with Hotelling's 95\% confidence ellipse of Crataegi folium. (A) PCA of CS, CA and CK; (B) OPLS-DA of CS vs. CA and (C) OPLS-DA of CS vs. CK.

To explore the difference between the leaves of CS and CK/CA, the score plot from the OPLS-DA model was conducted. In terms of the model of CS and CA, $R^{2} X, R^{2} Y$ and $\mathrm{Q}^{2}$ were $0.857,0.973$ and 0.972 and for the model of CS and CK they were $0.882,0.989$ and 0.988 respectively, which showed these models with a goodness of fit. The OPLS-DA scores plot (Figure 6B,C) showed a good separation between CS and CA, CS and CK, which expressed the difference of the content of flavonoids compounds in different species. Combined S-plot and VIP, by filtering the compounds of VIP $>1$, we discovered rutin, vitexin-2"-O-glucoside, vitexin-2"-O-rhamnoside and vitexin were the grater contribution to the variance between CS vs. CK (Figure 7A,B). Vitexin-2"-O-rhamnoside, vitexin-2"$O$-glucoside and rutin were the main contributions between CS vs. CA (Figure 7C,D). As a result, vitexin-2"-O-rhamnoside, vitexin-2"-O-glucoside and rutin were the major markers as crucial active compounds in the leaves of CS, CA and CK compared with other species [27]. What is more, CS was suitable for further exploration. 

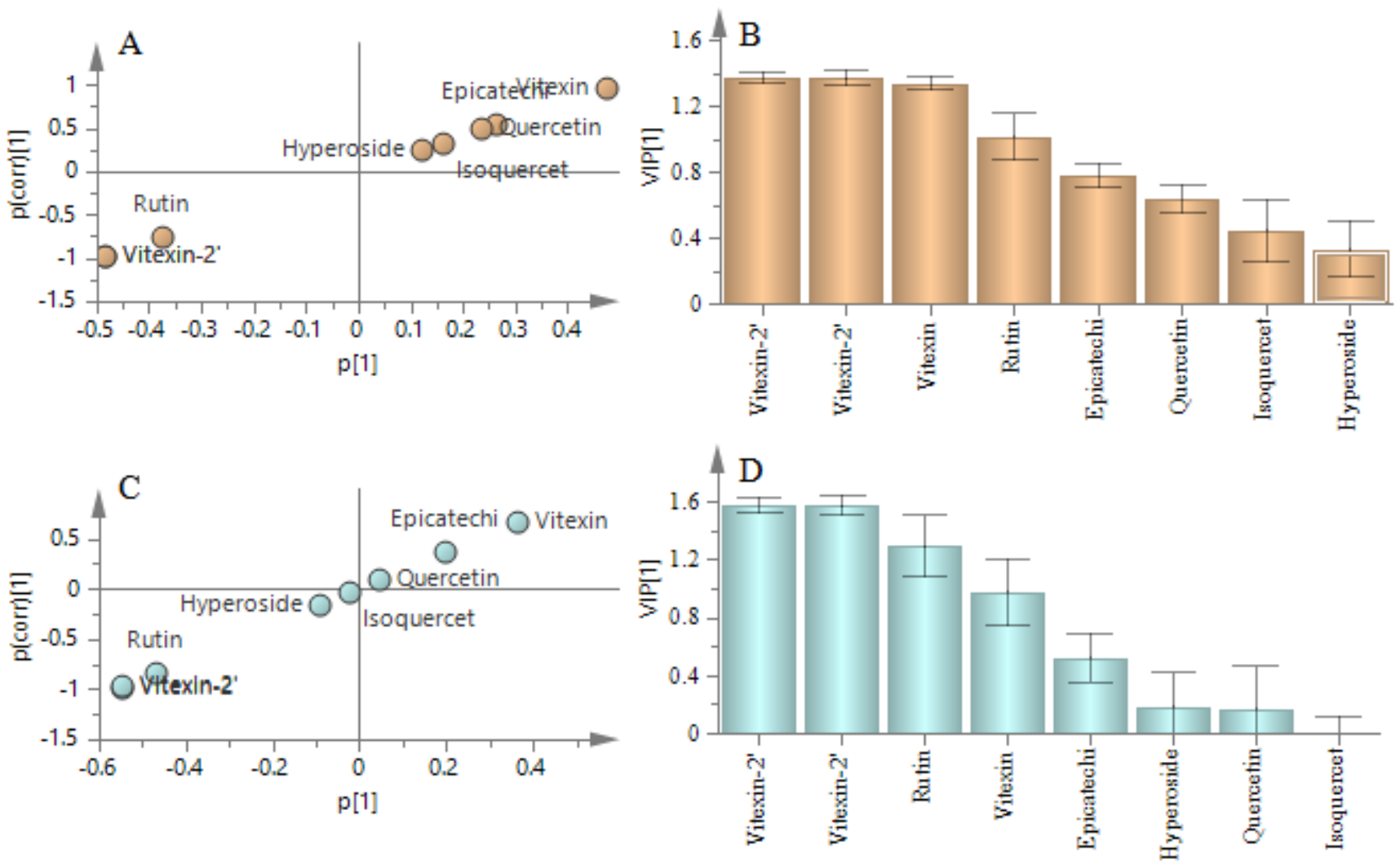

Figure 7. The statistical analysis of the content of eight flavonoids compounds S-plot from OPLS-DA of CS vs. CK (A), CS vs. CA (C) and variable importance plot (VIP) with 95\% jack-knifed confidence intervals of CS vs. CK (B) and CS vs. CA (D).

\subsubsection{Comparative Analysis of Different Harvesting Periods of Crataegi folium}

Figure $8 \mathrm{~A}$ showed the various levels of eight flavonoids in the leaves of CS. The contents of epicatechin, hyperoside and isoquercetin remained the same trend in the whole harvesting period and increased progressively in September until reaching the highest levels on 26th September, and decreased after that, however, the content of vitexin-2"-Orhamnoside reached the highest level $(8.2 \mathrm{mg} / \mathrm{g})$ in 10th September and reduced to the lowest level $(6.0 \mathrm{mg} / \mathrm{g})$ in 26th September and rose slowly by the end of the harvesting period. Quercetin and vitexin-2"-O-glucoside always stayed stable in the whole harvesting period, which may be a result from the low content. Moreover, vitexin and rutin achieved the highest levels on 26th September and decreased after that which were consistent with epicatechin, hyperoside and isoquercetin. For most of the content of all compounds, the vitexin-2"-O-rhamnoside was the highest one. In a word, the best harvesting period should be from 17th to 26th September of the leaves of CS. 

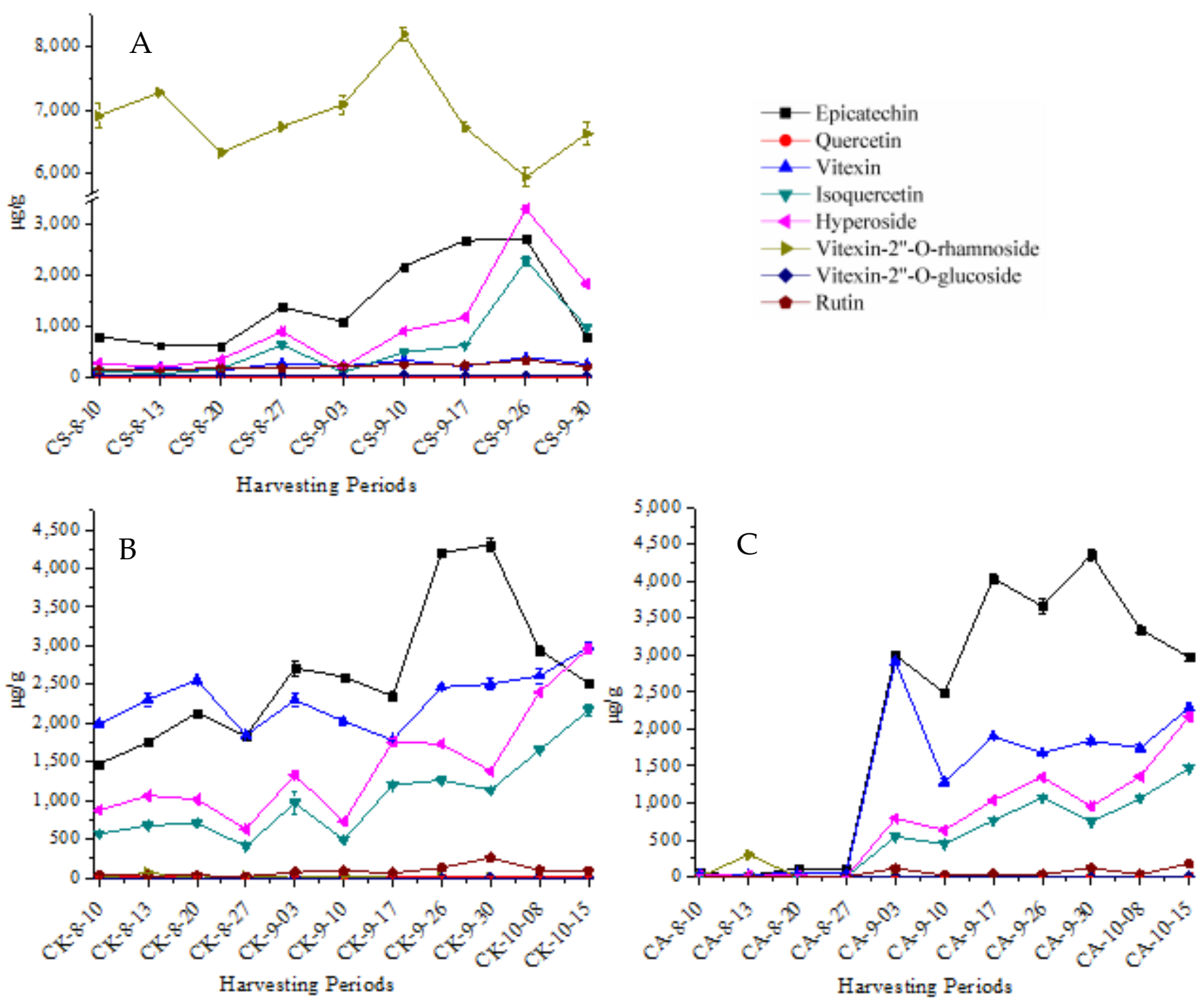

Figure 8. Changes in the content of eight flavonoids in leaves of CS (A), CK (B) and CA (C) during different harvesting. periods $(n=3)$.

Figure $8 \mathrm{~B}$ presented the changing patterns in the content of eight flavonoids in the leaves of $\mathrm{CK}$, hyperoside and isoquercetin remained the same trend in whole harvesting period, before 17th September, epicatechin and vitexin kept accordance in CK, but epicatechin gained the highest levels on 30th September, hyperoside, isoquercetin and vitexin increased the highest in 15th October because of correlation between contents of quercetin derivatives. The accumulation of flavonoids in leaves was commonly suggested to be sensitive to the environment. A negative correlation has been found between the contents of quercetin derivatives in tomato leaves and harvesting temperature [28]. The other compounds remained constant in the whole harvesting period. Consequently, the best harvesting period should be in from 30th September to 15th October of the leaves of CK.

Figure $8 \mathrm{C}$ expressed the varied trend the content of eight flavonoids in the leaves of CA, 27th August was a key date for CA, after that, the content of epicatechin, vitexin, hyperoside and isoquercetin of CA increasing sharply in early September, and then vitexin attained the highest content in 3rd September, and decreased quickly in 10th September, after that increasing slowly, until the end of harvesting period reattained the secondhighest level. After 27th August, epicatechin continued to grow, until it increased up to the highest level on 30th September and then reduced slowly. The trends of hyperoside and isoquercetin were in accordance with CK. In general, the change of the content of eight 
flavonoids in CK and CA were similar. Therefore, the best harvesting period should be from 30th September to 15th October of the leaves of CK, and CK was an alternative species to study the content of eight flavonoids in different parts in the next research.

To further explore the similarity and difference of leaves in different harvesting periods, the PCA and OPLS-DA models were built as shown in Figure 9. According to the hierarchical clustering analysis (HCA) (Supporting information), and the Euclidean distance and Ward clustering algorithm were selected, the scores plot of PCA $\left(\mathrm{R}^{2} \mathrm{X}\right.$ and $\mathrm{Q}^{2}$ (cum) were 0.984 and 0.893 ) in the harvesting period of CS was divided into two groups of harvesting period, which were from 10th August to 3th September (the blue color) and from 3rd September to 30th September (the gold color) shown in Figure 9A, the scores plot of OPLS-DA $\left(R^{2} X, R^{2} Y\right.$ and $Q^{2}$ were $0.997,0.981$ and 0.953$)$ had a good separation in Figure $9 \mathrm{~B}$, which demonstrated a marked difference in two groups. Combining S-plot of OPLS-DA and VIP, by filtering the compounds of VIP $>1$, we discovered rutin, quercetin, hyperoside, isoquercetin, vitexin and epicatechin were primarily markers in two harvesting periods. It suggested there were remarkable changes in August and September in the content of rutin, quercetin, hyperoside, isoquercetin, vitexin and epicatechin.
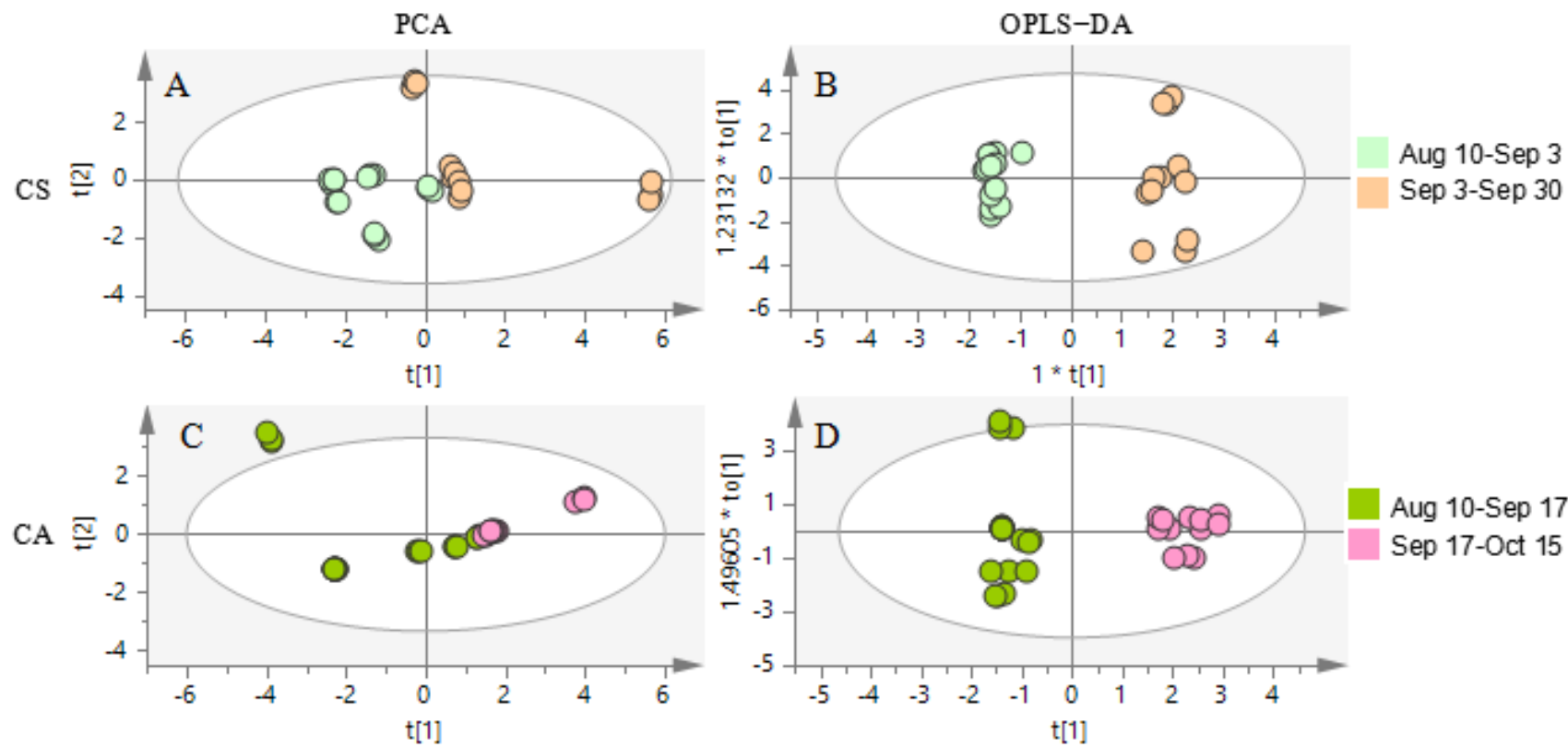

Aug 10-Sep 17 Sep 17-Oct 15 CK
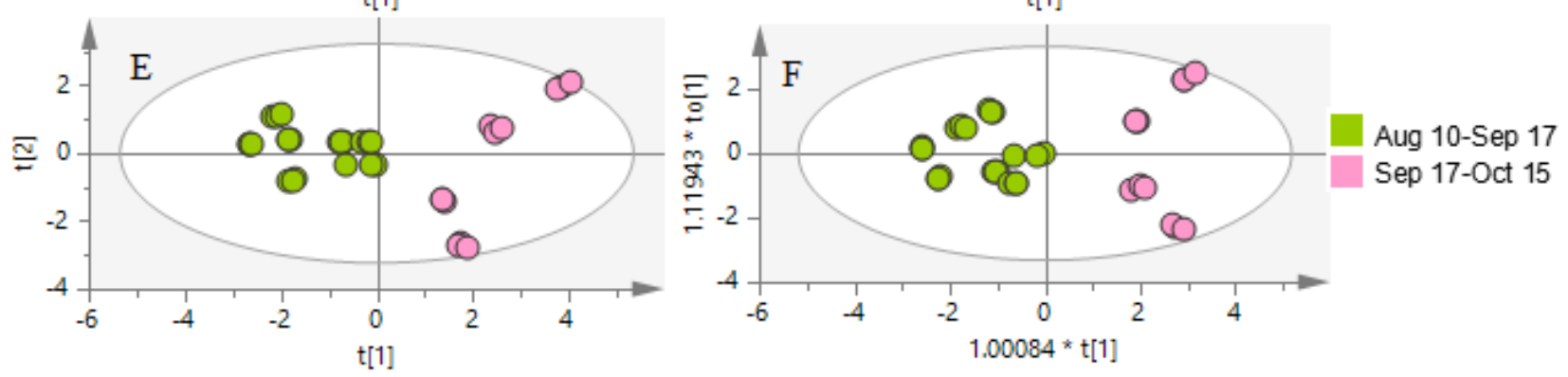

Figure 9. The statistical analysis of the content of eight flavonoids compounds score plot from PCA and OPLS-DA model with Hotelling's 95\% confidence ellipse of the leaves of CS, CA and CK in different harvesting period. (A) PCA in Aug 10-Sep 3 and Sep 3-Sep 30 of CS; (B) OPLS-DA in Aug 10-Sep 3 and Sep 3-Sep 30 of CS; (C) PCA in Aug 10-Sep 17 and Sep 17-Oct 15 of CA; (D) OPLS-DA in Aug 10-Sep 17 and Sep 17-Oct 15 of CA; (E)PCA in Aug 10-Sep 17 and Sep 17-Oct 15 of CK and (F) OPLS-DA in Aug 10-Sep 17 and Sep 17-Oct 15 of CK.

The same procedure was carried out separately for CA and CK, based on HCA (Supporting information), the scores plot of PCA for CA (Figure 9C) and CK (Figure 9E), $\mathrm{CA}$ and CK was divided into two same groups of harvesting period, which were from 10th August to 17th September (the green color) and from 17th September to 15th October 
(the pink color). The $\mathrm{R}^{2} \mathrm{X}$ and $\mathrm{Q}^{2}$ (cum) of the PCA model of CA were 0.984 and 0.905, and CK were 0.820 and 0.415 and the $R^{2} X, R^{2} Y$ and $Q^{2}$ of scores plot of OPLS-DA of CA (Figure 9D) were 1.000, 0.970 and 0.952, and CK (Figure 9F) were 0.795, 0.876 and 0.860 . Combined S-plot of OPLS-DA and VIP, by filtering the compounds of VIP $>1$, we found quercetin, hyperoside, isoquercetin and epicatechin were common markers, which may be relevant with temperature [28].

\subsubsection{Comparison with the Content of Eight Flavonoids in Different Parts of CS and CK}

In the current study, samples of fruits, branches and leaves of CS and CK were picked on 17th September based on the best harvesting period of leaves. Detailed data were shown in Table S3. Vitexin-2"-O-rhamnoside and vitexin-2"-O-glucoside mainly existed in the leaf of CS, hyperoside, isoquercetin, vitexin and epicatechin mostly were detected in the leaf of CK. Unfortunately, vitexin-2"-O-rhamnoside and vitexin-2"-O-glucoside were not detected in the branches of CK and CS, and vitexin-2"-O-glucoside were not detected in the fruit of CS in Figure 10A. In addition, the content of hyperoside, isoquercetin, vitexin, rutin, quercetin and epicatechin were higher in leaves than branches and fruit in Figure 10B. Compared with different parts, we discovered the content of total flavonoids in leaves of CS and CK were 11.7 and $7.2 \mathrm{mg} / \mathrm{g}$ were highest. Moreover, the total flavonoids in branches of CS and CK were 1.6 and $2.0 \mathrm{mg} / \mathrm{g}$, and the lowest content were 0.55 and $0.69 \mathrm{mg} / \mathrm{g}$ in the fruit of CS and CK in Table S3. Overall, the leaf as the primary part of food and medicinal material was in reason.

A

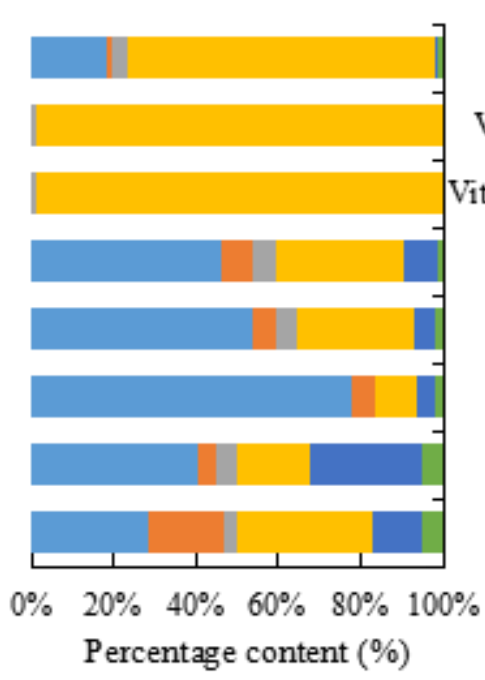

B

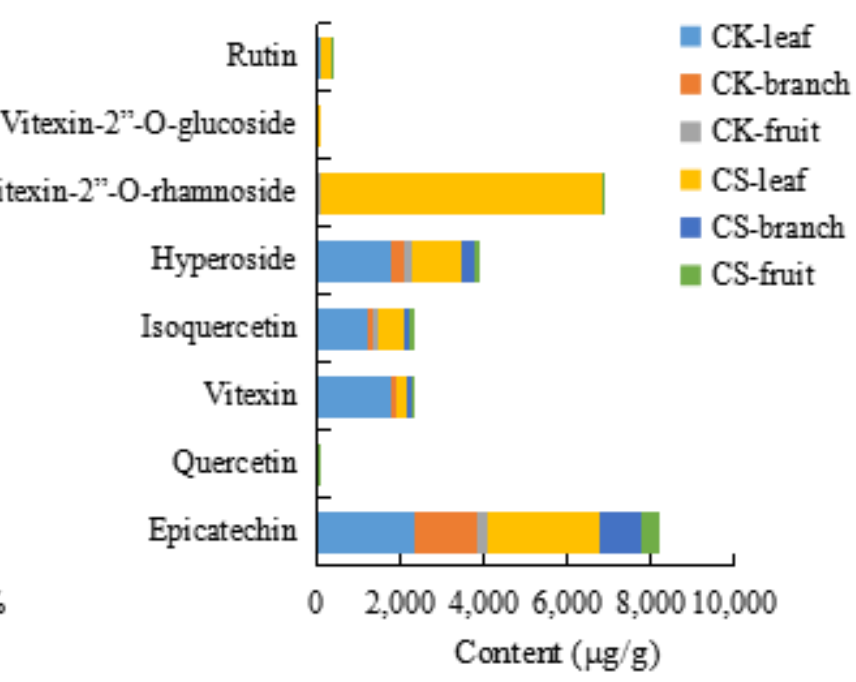

Figure 10. The content of eight flavonoids compounds in different parts of CS and CK. (A) Percentage stacked column of eight flavonoids compounds. (B) Stacked column of eight flavonoids compounds.

\subsubsection{The Content of Eight Flavonoids in the Leaves of CS and C. pinnatifida}

In the current study, the collected leaves of CS on 17th and 26th September were selected to compare with $C$. pinnatifida (CP) according to the previous study. As shown in Figure $11 \mathrm{~A}$, the content of epicatechin, quercetin, isoquercetin, hyperoside, vitexin-2"-Orhamnoside and rutin were higher in CS than $\mathrm{CP}$, but the content of vitexin-2"-O-glucoside and vitexin were lower in CS than $\mathrm{CP}$, what is more, the content of epicatechin in CS was about 270 times than in $\mathrm{CP}$, hyperoside was almost 100 times, and isoquercetin and rutin were approximately 10 times. In addition, the total content of flavonoids in CS was higher than CP in Figure 11B, which suggested the leaves of CS were potential and valuable food and medicinal material. 

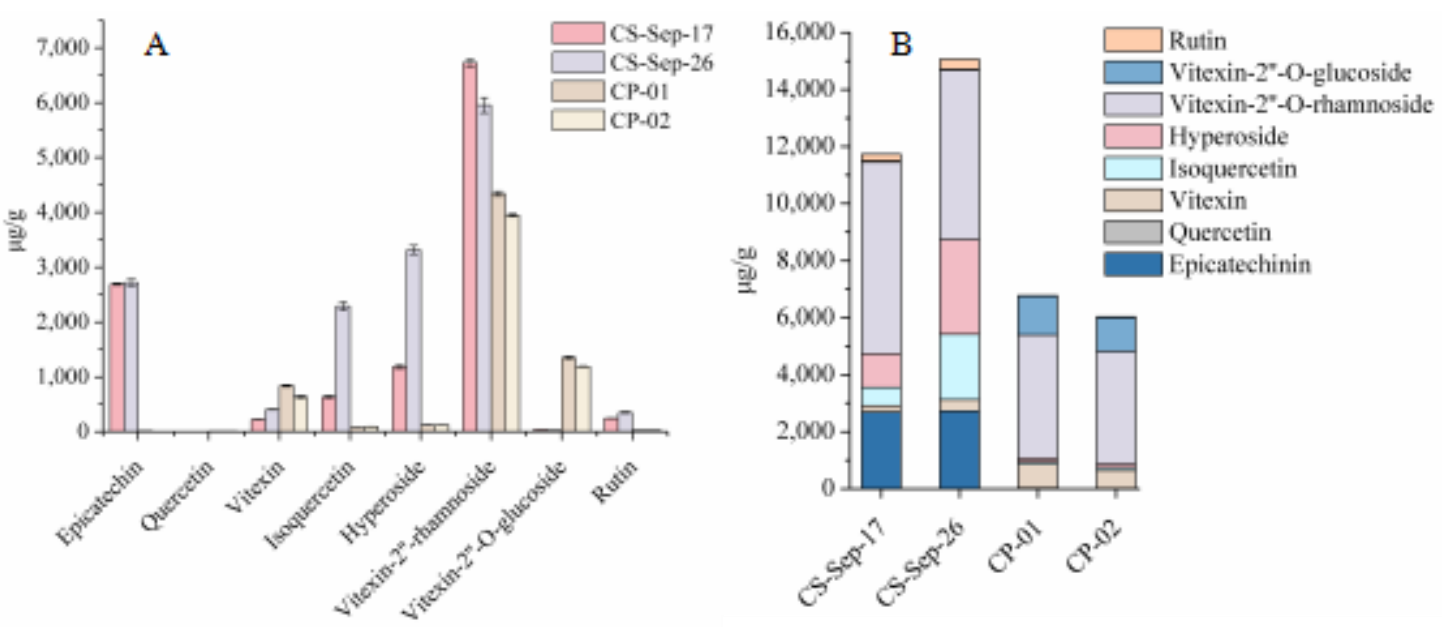

Figure 11. The content of eight flavonoids compounds in CS and CP. (A) Column of content of eight flavonoids compounds. (B) Stack column of content of eight flavonoids compounds.

\section{Materials and Methods}

\subsection{Reagents and Materials}

LC-MS grade acetonitrile and formic acid were purchased from Fisher Scientific (Loughborough, UK). HPLC grade methanol was obtained from Sigma-Aldrich (St. Louis, MO, USA). Deionized water (18.2 $\Omega$ ) was further purified using a Milli-Q system from Millipore (Milford, MA, USA). Oasis ${ }^{\circledR}$ PRiME HLB Cartridge Plus Short (335 mg) was provided by Waters Technologies (Milford, MA, USA). Eight flavonoids standards, rutin, quercetin, hyperoside, isoquercetin, vitexin-2"-O-glucoside, vitexin-2"-O-rhamnoside, vitexin, and epicatechin, were provided by Chengdu Must Bio-Technology CO., Ltd. (Chengdu, Sichuan, China). The purity of these standards was no less than 98\%. All chemicals used for extraction were of analytical grade.

The leaves of different harvesting periods, fruit and branches of CS, CA and CK were collected from Xinjiang Academy of Forestry, Urumqi, Xinjiang, China and authenticated by Senior Scientist Hong Li (Xinjiang Academy of Forestry Sciences, Key Laboratory of Fruit tree Species Breeding and Cultivation in Xinjiang, Urumqi, China). The leaves of CS, CA and CK were collected once a week at the same time from August 10, 2020, until the leaves fell out. The leaves of CS were gathered in 9 batches of samples until September 30, 2020, CA and CK were in 11 batches until October 15, 2020. Additionally, the fruit and branches of CS and CK were picked in September 17, 2020. Moreover, Crataegus pinnatifida were purchased in Xiamen Shouyi Zhenyuan Health Management Co., Ltd. (Xiamen, Fujian, China).

\subsection{UPLC-Q-TOF-MS Analysis}

The instrument used was Acquity UPLC I-class system with an Acquity UPLC BEH C18 column $(100 \mathrm{~mm} \times 2.1 \mathrm{~mm}, 1.7 \mu \mathrm{m}$ particles) from Wates Technologies (Milford, MA, USA) was used at $40{ }^{\circ} \mathrm{C}$, and the samples were kept at $4{ }^{\circ} \mathrm{C}$. A binary solvent system was employed consisting of solvent A (water containing $0.1 \%$ formic acid) and solvent $B$ (acetonitrile). The gradient program was 0-10 min with 5-13\% solvent B, 10-15 min with $13-20 \% \mathrm{~B}, 15-18 \mathrm{~min}$ with $20-50 \% \mathrm{~B}$ and $18-20 \mathrm{~min}$ with $50-95 \% \mathrm{~B}$. The injection volume was $2 \mu \mathrm{L}$ and the flow rate was set at $0.4 \mathrm{~min} / \mathrm{L}$.

Xevo G2-XS Q-TOF from Wates Technologies (Milford, MA, USA) equipped with electrospray ionization ion (ESI) source was applied for mass spectrometry data acquisition in negative ionization mode ranged from $m / z 50-1200$ Da in the profile mode. The lock mass compound was leucineenk-ephalin ( $\mathrm{m} / \mathrm{z} 554.2615)$, its concentration was $200 \mathrm{pg} / \mathrm{mL}$. The ion scan mode adopted the MSE mode. The electrospray capillary voltage was set to $2.5 \mathrm{kV}$, the cone voltage was set to $40 \mathrm{~V}$. The source temperature was $110^{\circ} \mathrm{C}$ and desolvation 
temperature $450{ }^{\circ} \mathrm{C}$. The low energy was $4 \mathrm{eV}$ and the high energy ramp from 30 to $50 \mathrm{~V}$. The cone gas flow was $50 \mathrm{~L} / \mathrm{h}$ and desolvation gas flow $800 \mathrm{~L} / \mathrm{h}$; nitrogen and argon were used as the nebulizer and the collision gas respectively. The UPLC-Q-TOF-MS system was operated by MassLynx 4.1 software.

\subsection{UPLC-TQ-MS Analysis}

The instrument used was Acquity UPLC I-class system with an Acquity UPLC BEH C18 column (100 $\mathrm{mm} \times 2.1 \mathrm{~mm}, 1.7 \mu \mathrm{m}$ particles) from Wates Technologies (Milford, MA, USA) was used at $40{ }^{\circ} \mathrm{C}$ and the samples were kept at $4{ }^{\circ} \mathrm{C}$. A binary solvent system was employed consisting of solvent $\mathrm{A}$ (water containing $0.1 \%$ formic acid) and solvent $\mathrm{B}$ (acetonitrile). The gradient program was 0-2 min with $15 \%$ solvent B, 2-5 min with $15-40 \%$ $\mathrm{B}$ and $5-6 \mathrm{~min}$ with $40-95 \% \mathrm{~B}$. The injection volume was $2 \mu \mathrm{L}$ and the flow rate was set at $0.4 \mathrm{~mL} / \mathrm{min}$.

Xevo TQ from Wates Technologies (Milford, MA, USA) equipped with the electrospray ionization ion (ESI) source was applied for mass spectrometry data acquisition in the negative ionization mode. The ion scan mode was adopted the MRM (multiple reaction monitoring) mode. The electrospray capillary voltage was set to $2.5 \mathrm{kV}$, the cone voltage was set to $40 \mathrm{~V}$. The source temperature was $110^{\circ} \mathrm{C}$ and desolvation temperature $450{ }^{\circ} \mathrm{C}$. The cone gas flow was $50 \mathrm{~L} / \mathrm{h}$ and desolvation gas flow $800 \mathrm{~L} / \mathrm{h}$; nitrogen and argon were used as the nebulizer and the collision gas respectively. The UPLC TQ MS system was controlled by MassLynx 4.1 software. The ions of quantitative analysis were monitored with rutin $(609.3130 \rightarrow 300.1526)$, quercetin $(301.2661 \rightarrow 151.0383)$, hyperoside $(463.3189 \rightarrow 300.1985)$, isoquercetin (463.3189 $\rightarrow 271.0959)$, vitexin-2"-O-glucoside $(593.3180 \rightarrow 293.1144)$, vitexin2"-O-rhamnoside (577.3231 $\rightarrow$ 293.1127), vitexin $(431.3290 \rightarrow 311.1557)$ and epicatechin (289.3025 $\rightarrow$ 245.1585).

\subsection{Sample Preparation}

Samples were dried to a constant weight under vacuum drying process, crushed in a ball crusher. Different samples accurately were weighed $250 \mathrm{mg}$ and mixed with $5 \mathrm{~mL}$ methanol respectively. All the prepared samples were subjected to an ultrasonic bath for $30 \mathrm{~min}$, cooled down, made up for weightlessness and then centrifuged for $5 \mathrm{~min}$ at $10,000 \mathrm{rpm}$ with $4{ }^{\circ} \mathrm{C}$. To Oasis ${ }^{\circledR}$ PRiME HLB Cartridge (SPE) $1 \mathrm{~mL}$ supernatant was added, and then $4 \mathrm{~mL}$ of methanol was eluted to a $5 \mathrm{~mL}$ volumetric flask and methanol was added to bring the volume to the scale and mixed thoroughly. All samples were filtered through a $0.22 \mu \mathrm{m}$ syringe filter before analysis. Besides, three replicates were prepared for every sample. Then, a mixed quality control (QC) sample was prepared by pooled $100 \mu \mathrm{L}$ of each sample for qualitative analysis, and the QC sample injections were used for the initial equilibration of the LC-MS system (4-5 injections) and one QC sample injected every 7 real sample injections during the list [26].

\subsection{Quantitative Method Validation}

In this paper, the 8 flavonoids compounds detected by the reference substance were quantitatively analyzed. Eight flavonoid standards were dissolved in methanol to prepare the mother liquor with the concentration of $1.0 \mathrm{mg} / \mathrm{mL}$ respectively, and then 8 mixed reference substances were progressively diluted to $10 \mu \mathrm{g} / \mathrm{mL}$. Finally, $10 \mu \mathrm{g} / \mathrm{mL}$ was diluted to a suitable concentration step by step for injection. Into the UPLC TQ MS system for each batch of standard samples $2 \mu \mathrm{L}$ was injected. The established method for quantitative analysis was validated by the linearity, limit of detection (LOD), limit of quantification (LOQ) accuracy, repeatability and recovery. The linear equation was performed with the peak area of reference as $Y$-axis and the concentration of reference substance as $\mathrm{x}$-axis, the weighing was $1 / \mathrm{x}$ and the calibration curve of every compound was performed by at least five different concentrations. Some samples beyond the linear range, which were diluted to the linear range before evaluation. 


\subsection{Data Analysis}

Qualitative data were analyzed by Progenesis QI (nonlinear dynamics, version 2.4), the parameters were conducted by default, except for data processing because only the 0.5-21 min range was selected. On the other hand, statistical analyses of the quantitative data were conducted by OriginPro 8.0 (OriginLab Corporation), and the PCA and OPLS-DA models were generated in SIMCA 13.0 (Umetrics AB).

\section{Conclusions}

Two hundred and sixteen compounds were identified and 28 unique compounds were screened in Crataegi folium from qualitative data, which could be used to distinguish different species of Crataegi folium. An efficient LC-MS/MS method was developed, validated and successfully implemented to the analysis of the content of eight flavonoid compounds within $6 \mathrm{~min}$ in CS, CA and CK, and their best harvesting period in leaves was optimal for effective utilization as medicinal and food materials. Additionally, as the $s$ result of high content of vitexin-2"-O-rhamnoside in the leaves of CS, it provided a theoretical basis for CS further research and quality control.

Supplementary Materials: The following are available online, Figure S1: The HCA plot in different harvesting period of the leaves of CS (A), CA (B) and CK (C), Figure S2: The relative content of 28 unique compounds in the leaves of CS and CK in different harvesting periods, Table S1: 216 compounds information identified in the leaves of CS, CA and CK, Table S2: The content of eight flavonoids compounds of the leaves of CS, CA and CK, Table S3: The content of eight flavonoids compounds of different parts of CS and CK.

Author Contributions: Conceptualization, Y.-P.G., J.H. and L.Y.; methodology, Y.-P.G., H.Y., L.Y., and J.H; software, Y.-P.G., and J.H.; validation, Y.-P.G. and H.Y.; formal analysis, Y.-P.G., H.Y. and K.Z.; investigation, Y.-P.G., H.Y., Y.-L.W. (Ya-Li Wang) and X.-X.C.; data curation, Y.-P.G., H.Y., Y.-F.S. and Y.-L.W. (Yan-Li Wang); writing—original draft preparation, Y.-P.G. and H.Y.; writing—review and editing, Y.-P.G., J.H., and L.Y.; supervision, J.H., J.-H.W. and L.Y. All authors have read and agreed to the published version of the manuscript.

Funding: This research was funded by National Science and Technology Major Project of the Ministry of Science and Technology of China, grant number 2018ZX09735005 and Harbin Medical University Scientific Research Projects, grant number YJSKYCX2019-21HYD.

Institutional Review Board Statement: Not applicable.

Informed Consent Statement: Not applicable.

Data Availability Statement: Not applicable.

Acknowledgments: We wish to acknowledge Shuyun Wang and Dahong Yao for their technical support.

Conflicts of Interest: The authors declare no conflict of interest. The funders had no role in the design of the study; in the collection, analyses, or interpretation of data; in the writing of the manuscript, or in the decision to publish the results.

Sample Availability: Not available.

\section{References}

1. Liu, P.; Kallio, H.; Lü, D.; Zhou, C.; Yang, B. Quantitative analysis of phenolic compounds in Chinese hawthorn (Crataegus spp.) fruits by high performance liquid chromatography-electrospray ionisation mass spectrometry. Food Chem. 2011, 127, 1370-1377. [CrossRef]

2. Liu, P.; Kallio, H.; Yang, B. Phenolic compounds in hawthorn (Crataegus grayana) fruits and leaves and changes during fruit ripening. J. Agric. Food Chem. 2011, 59, 11141-11149. [CrossRef]

3. Wang, T.; An, Y.; Zhao, C.; Han, L.; Boakye-Yiadom, M.; Wang, W.; Zhang, Y. Regulation effects of Crataegus pinnatifida leaf on glucose and lipids metabolism. J. Agric. Food Chem. 2011, 59, 4987-4994. [CrossRef]

4. Akila, M.; Devaraj, H. Synergistic effect of tincture of Crataegus and Mangifera indica L. extract on hyperlipidemic and antioxidant status in atherogenic rats. Vasc. Pharmacol. 2008, 49, 173-177. [CrossRef] [PubMed] 
5. Pittler, M.H.; Schmidt, K.; Ernst, E. Hawthorn extract for treating chronic heart failure: Meta-analysis of randomized trials. Am. J. Med. 2003, 114, 665-674. [CrossRef]

6. Elango, C.; Devaraj, S.N. Immunomodulatory effect of Hawthorn extract in an experimental stroke model. J. Neuroinflammation. 2010, 30, 7-97. [CrossRef] [PubMed]

7. Walker, A.F.; Marakis, G.; Simpson, E.; Hope, J.L.; Robinson, P.A.; Hassanein, M.; Simpson, H.C. Hypotensive effects of hawthorn for patients with diabetes taking prescription drugs: A randomised controlled trial. Br. J. Gen. Pract. 2006, 56, 437-443.

8. Melikoğlu, G.; Bitiş, L.; Meriçli, A.H. Flavonoids of Crataegus microphylla. Nat. Prod. Res. 2004, 18, 211-213. [CrossRef]

9. Ying, X.; Wang, R.; Xu, J.; Zhang, W.; Li, H.; Zhang, C.; Li, F. HPLC determination of eight polyphenols in the leaves of Crataegus pinnatifida Bge. var. major. J. Chromatogr. Sci. 2009, 47, 201-205. [CrossRef]

10. Zhang, P.C.; Xu, S.X. C-glucoside flavonoids from the leaves of Crataegus pinnatifida Bge. var. major N.E.Br. J. Asian Nat. Prod. Res. 2003, 5, 131-136. [CrossRef]

11. Veveris, M.; Koch, E.; Chatterjee, S.S. Crataegus special extract WS 1442 improves cardiac function and reduces infarct size in a rat model of prolonged coronary ischemia and reperfusion. Life Sci. 2004, 74, 1945-1955. [CrossRef]

12. Dong, P.; Pan, L.; Zhang, X.; Zhang, W.; Wang, X.; Jiang, M.; Chen, Y.; Duan, Y.; Wu, H.; Xu, Y.; et al. Hawthorn (Crataegus pinnatifida Bunge) leave flavonoids attenuate atherosclerosis development in apoE knock-out mice. J. Ethnopharmacol. 2017, 198, 479-488. [CrossRef] [PubMed]

13. Li, P.; Wang, J.; Lu, S.; Fu, J.; Liu, J. Protective effect of hawthorn leaf procyanidins on cardiomyocytes of neonatal rats subjected to simulated ischemia-reperfusion injury. Zhongguo Zhong Yao Za Zhi. 2009, 34, 96-99. [PubMed]

14. Asgary, S.; Naderi, G.H.; Sadeghi, M.; Kelishadi, R.; Amiri, M. Antihypertensive effect of Iranian Crataegus curvisepala Lind.: A randomized, double-blind study. Drugs Exp. Clin. Res. 2004, 30, 221-225.

15. Fu, J.H.; Zheng, Y.Q.; Li, P.; Li, X.Z.; Shang, X.H.; Liu, J.X. Hawthorn leaves flavonoids decreases inflammation related to acute myocardial ischemia/reperfusion in anesthetized dogs. Chin. J. Integr. Med. 2013, 19, 582-588. [CrossRef] [PubMed]

16. Tadić, V.M.; Dobrić, S.; Marković, G.M.; Dordević, S.M.; Arsić, I.A.; Menković, N.R.; Stević, T. Anti-inflammatory, gastroprotective, free-radical-scavenging, and antimicrobial activities of hawthorn berries ethanol extract. J. Agric. Food Chem. 2008, 56, 7700-7709. [CrossRef] [PubMed]

17. Pittler, M.H.; Guo, R.; Ernst, E. Hawthorn extract for treating chronic heart failure. Cochrane Database Syst. Rev 2008, 1, CD005312.

18. Ma, G.; Jiang, X.H.; Chen, Z.; Ren, J.; Li, C.R.; Liu, T.M. Simultaneous determination of vitexin-4"-O-glucoside and vitexin-2"-Orhamnoside from Hawthorn leaves flavonoids in rat plasma by HPLC method and its application to pharmacokinetic studies. $J$. Pharm. Biomed. Anal. 2007, 44, 243-249. [CrossRef] [PubMed]

19. Ying, X.; Gao, S.; Zhu, W.; Bi, Y.; Qin, F.; Li, X.; Li, F. High-performance liquid chromatographic determination and pharmacokinetic study of vitexin-2"-O-rhamnoside in rat plasma after intravenous administration. J. Pharm. Biomed. Anal. 2007, 44, 802-806. [CrossRef]

20. Liu, W.; Chen, G.; Cui, T. Determination of flavones in Crataegus pinnatifida by capillary zone electrophoresis. J. Chromatogr. Sci. 2003, 41, 87-91. [CrossRef]

21. Wen, L.; Lin, Y.; Lv, R.; Yan, H.; Yu, J.; Zhao, H.; Wang, X.; Wang, D. An Efficient Method for the Preparative Isolation and Purification of Flavonoids from Leaves of Crataegus pinnatifida by HSCCC and Pre-HPLC. Molecules 2017, 22, 767. [CrossRef] [PubMed]

22. Ying, X.; Lu, X.; Sun, X.; Li, X.; Li, F. Determination of vitexin-2"-O-rhamnoside in rat plasma by ultra-performance liquid chromatography electrospray ionization tandem mass spectrometry and its application to pharmacokinetic study. Talanta 2007, 72, 1500-1506. [CrossRef] [PubMed]

23. Liu, H.; Liao, K.; Xiaoqin, A.; Shirong, Z.; Xiaolong, L. Pollen Viability in Three Xinjiang Hawthorn Species. J. Agric. Sci. E Tech. 2014, 15, 550-553.

24. Plazas, E.; Casoti, R.; Avila, M.; Batista Da Costa, F.; Cuca, L.E. Metabolomic profiling of Zanthoxylum species: Identification of anti-cholinesterase alkaloids candidates. Phytochemistry 2019, 168, 112128. [CrossRef]

25. Wiklund, S.; Johansson, E.; Sjöström, L.; Mellerowicz, E.J.; Edlund, U.; Shockcor, J.P.; Gottfries, J.; Moritz, T.; Trygg, J. Visualization of GC/TOF-MS-based metabolomics data for identification of biochemically interesting compounds using OPLS class models. Anal. Chem. 2008, 80, 115-122. [CrossRef] [PubMed]

26. Arapitsas, P.; Ugliano, M.; Marangon, M.; Piombino, P.; Rolle, L.; Gerbi, V.; Versari, A.; Mattivi, F. Use of Untargeted Liquid Chromatography-Mass Spectrometry Metabolome To Discriminate Italian Monovarietal Red Wines, Produced in Their Different Terroirs. J. Agric. Food Chem. 2020, 68, 13353-13366. [CrossRef] [PubMed]

27. Prinz, S.; Ringl, A.; Huefner, A.; Pemp, E.; Kopp, B. 4"-Acetylvitexin-2"-O-rhamnoside, isoorientin, orientin, and 8methoxykaempferol-3-O-glucoside as markers for the differentiation of Crataegus monogyna and Crataegus pentagyna from Crataegus laevigata (Rosaceae). Chem. Biodivers. 2007, 4, 2920-2931. [CrossRef] [PubMed]

28. Løvdal, T.; Olsen, K.M.; Slimestad, R.; Verheul, M.; Lillo, C. Synergetic effects of nitrogen depletion, temperature, and light on the content of phenolic compounds and gene expression in leaves of tomato. Phytochemistry 2010, 71, 605-613. [CrossRef] 